\title{
$\ddot{a} \Omega$ ol الملك لنعود \\ King Saud University

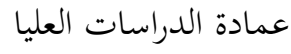

كلية الآداب/قسم الدراسات الاجتماعية

الآثار الاجتماعية المترتبة على الإجراءات الاحترازية لإدارة جائحة كورونا في المملكة

العربية السعودية

أ.د: الجوهرة بنت فهد الزامل

أستاذ الخدمة الإجتماعية بقسم الدراسات الإجتماعية - جامعة الملك سعود

2020- 1441

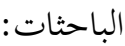

ابتهال أبو بكر باخطيب أحلام ضيف الله العتبيي أسياف عبدالله الحربي

أصالة عبد الرممن كنبيجه بشائر غبير حكمي بشاير علي اللويش

جميلة فيصل الشمري حصة عبدالله بن شاهين رند صالح الجروان

العنود نوار المقاطي لوة ناصر الدوسري مطلة خالد الخمعلي

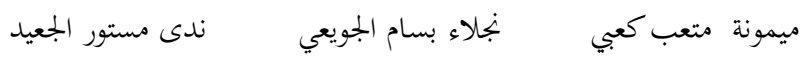

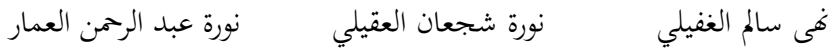


بسم الله الرحمن الرحيم

" وقل ربي زدلي علما "

آية 114 سورة طه 
ملخص الدراسة

استهدفت هذه الدراسة الكثف عن اتجاهات الشعب السعودي حول الإجراءات الاحترازية أثناء جائحة كورونا والآثار الاجتماعية المترتبة عليها.

تكون مجتمع الدراسة من (1952) موزعين على المناطق الإدارية الثلاثة عشر في المملكة العربية السعودية، وقد اعتمدت على منهج المستح

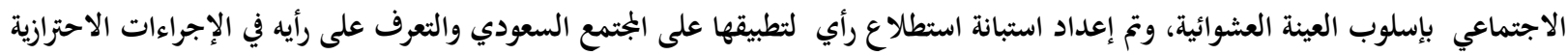

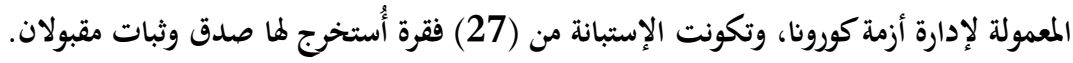

وقد أظهرت النتائج: أن اتجاهات أفراد الجتمع السعودي نحو الإجراءات الاحترازية أثناء جائحة كورونا تتمتع بمستوى عال أي أن غالبية أفراد مجتمع الئا

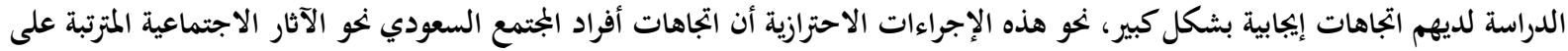

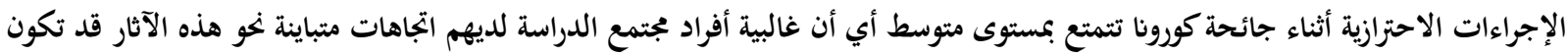

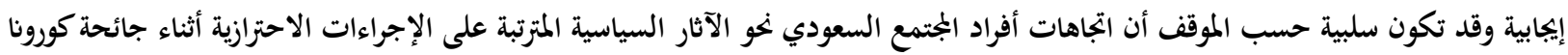

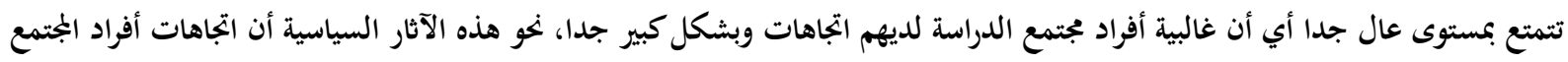

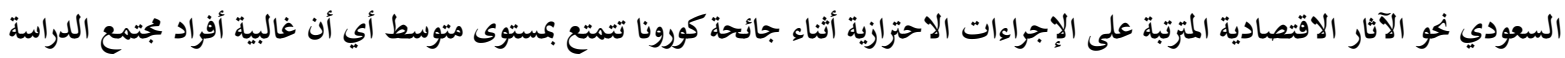
لديهم اتجاهات متباينة نحو هذه الآثار قد تكون إيجابية وقد تكون سلبية حسب الموقف أو أن هناك بعض الأفراد لدايهم التجاهات إيجابية والآخرين

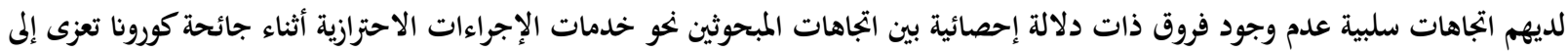

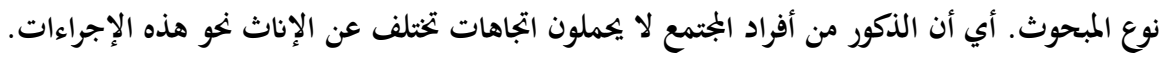

وقدمت الدراسة عدة توصيات جاء في أبرزها: تكثيف الدراسات والبحوث في مجال خطط الطوارئ، استغلال الإعلام الجديد لرفع مستوى الوعي في القضايا الجتمعية، دعم التقنية وتشجيع انتقال قطاعات الدولة لها، سن قوانين وتشريعات لسوق التجارة الالكترونية وأخيرًا قدمت تصور مقترح بناء على النتائج لدور الخدمة الاجتماعية في مجال التدخل في الأزمات والكوارث. الكلمات المفتاحية: الإجواءات الإحترازية، الآثار الاجتماعية ، كورونا، كوفيد19، كورونا السعودية، فيروس كورونا المستجد. 


\begin{abstract}
This descriptive study aims at discovering the attitudes of Saudi Arabia people towards the precautionary measures during covid-19 pandemic and the resulting effects. The study samples consists of (1952) distributed to the thirteen administrative regions in Saudi Arabia and after adoption of social survey approach, a questionnaire was prepared to identify the opinion of Saudi Arabia society in dealing with the precautionary measures to manage the covid-19 crisis. This study is formed of 27 paragraphs revealed acceptable honesty and consistency.
\end{abstract}

The results showed that attitudes of Saudi Arabians towards the precautionary measures during covid-19 pandemic are characterized by a high level which means the majority of the study samples have positive attitudes to a great extent towards these precautionary measures.

The attitudes of Saudi Arabians towards the social effects resulted of the precautionary measures during covid-19 pandemic are characterized by an intermediate level which means the majority of the study samples has varying attitudes towards these effects that may be positive or negative based on the situation. The attitudes of Saudi Arabians towards the political effects resulted of the precautionary measures during covid19 pandemic are characterized by a very high level which means the majority of the study samples significantly has positive attitudes towards these political effects. The attitudes of Saudi Arabians towards the economic effects resulted of the precautionary measures during covid-19 pandemic are characterized by an intermediate level which mean some of the study samples have positive attitudes and some of them have negative attitudes. There are no statistically significant differences between the attitudes of the interviewees towards services of the precautionary measures during covid-19 pandemic attributable to the interviewee gender.

The study suggests several recommendations highlighted by: intensification of research and studies in the field of emergency plans, making use of the new media to raise the awareness level regarding the social issues, supporting the technology and encouraging the public sectors to use it and enacting laws and legislations for the e-commerce market. Finally, based on the results the study presents a suggested proposal of the social services role in the field of crises and disasters interventions.

Key Words: Precautionary measures, social effects, Corona, Covid 19, Saudi Corona, the emerging corona virus. 
فهرس الختويات

\begin{tabular}{|c|c|}
\hline الصفحة & الموضوع \\
\hline 3 & ملخص الدراسة باللغة العربية \\
\hline 4 & ملخص الدراسة باللغة الإنجليزية \\
\hline 6 & مدخل إلى الدراسة \\
\hline 7 & مشكلة الدراسة \\
\hline 7 & أهمية الدراسة \\
\hline 8 & أهداف الدراسة \\
\hline 8 & تساؤلات الدراسة \\
\hline 8 & مفاهيم الدراسة \\
\hline 11 & الدراسات السابقة \\
\hline 14 & أدبيات الدراسة \\
\hline 19 & نوع الدراسة \\
\hline 19 & منهج الدراسة \\
\hline 19 & أداة الدراسة \\
\hline 19 & مجتمع الدراسة \\
\hline 19 & عينة الدراسة \\
\hline 19 & مجالات الدراسة \\
\hline 20 & نتائج الدراسة \\
\hline 21 & ت توصيات الدراسة \\
\hline 23 & المراجع \\
\hline
\end{tabular}


تؤكد الأحداث المتلاحقة والمتغيرات المفاجئة التي نقرأ ونسمع عنها في وسائل الإعلام المختلفة أننا نعيش في عالم تسوده العديد من الكوارث والأزمات

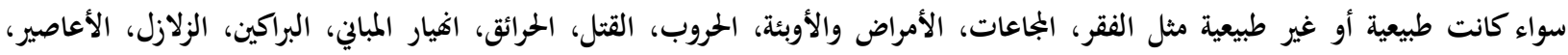

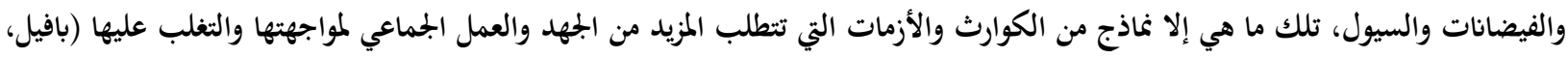

. $236: 2013$

وتمثل الأزمات الصحية تحديات ضخمة تواجه الجُتمعات البشرية، في الجتمع أو الدولة القادرة على وضع توقعات للأزمات والإعداد لمواجهتها تكون

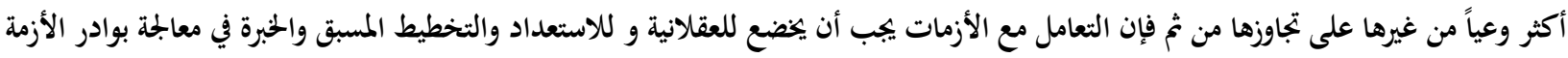

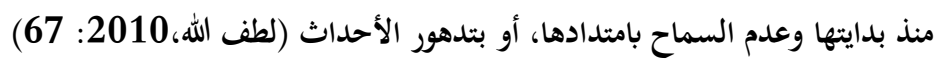
وتبذل دول العالم جهوداً من أجل الاستعداد للحالات الطارئة وخاصة حالة انتشار الأوبئة من خلال توفير المعرفة وتطوير القدرات والأنظمة التي يتم تطويرها من قبل الحكومات ومنظمات الاستجابة والتعافي والجُتمعات والأفراد، من أجل القيام بالتوقع والاستجابة والتعافي من آثار محتملة أو وشيكة التانية

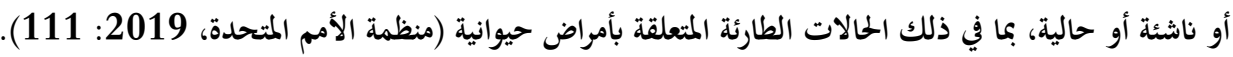
وتعتبر الأزمات الصحية الناتجة عن الأمراض الفيروسية من أكبر الأزمات التي تمدد وجود الإنسان وخاصة الأمراض التي تنتقل من الحيوان إلى الإنسان،

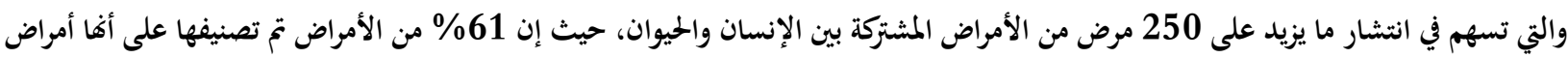
مشتركة بين الإنسان والحيوان (خلف الله، 2014: وظهر في القرن الرابع عشر بالتحديد في مطلع عام 1347م مرض الطاعون والذي حصد حياة أكثر من ·. . مليون من الأرواح في شتى نواحي العالم (جبر،2009: 2- 20

وفي عام 1918م ظهرت الأنفلونزا من النوع الجديد للمرة الأولى في فرنسا وزحفت إلى إسبانيا حيث أثارت فزع الشعب وأطلق عليها الأنفلونزا

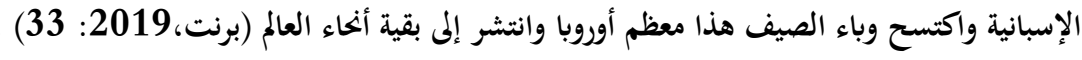
وفي عام 1919م أصاب الجدري الجزيرة العبية وتسبب في الكثير من الوفيات وخاصة وفيات الأطفال، وقدر عدد المصابين بما نسبته 70-80\%

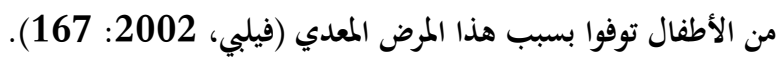
وأيضا كورونا ميرس - متلازمة الشرق الأوسط التنفسية - وهو من عائلة الفيروسات التاجية الحادة (السارس) الذي ظهر في الصين عام 2003م ثم

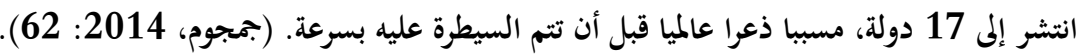
وكان هناك أيضا الفيروس الجديد سُمي متلازمة الالتهاب الرئوي التاجي الشرق أوسطي ، عُرف أيضاً بفيروس كورونا الشرق الأوسط، أو فيروس كورونا

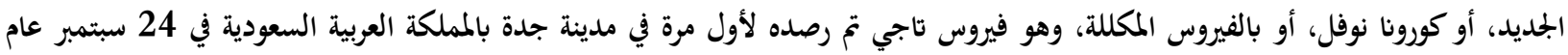

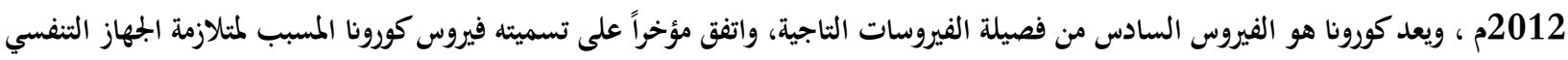

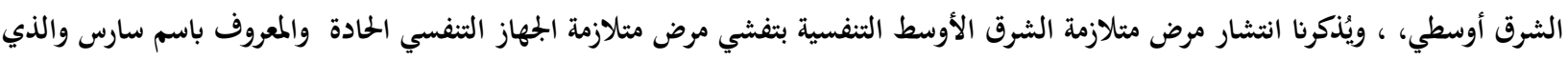

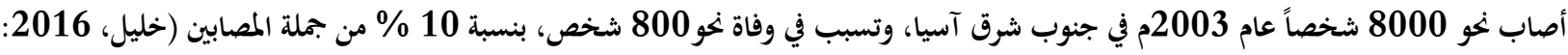

ثم ظهر بعد ذلك مرض كوفيد-19 هو مرض معد يسببه فيروس كورونا المككتشف مؤخراً، ولم يكن هناك أي علم بوجود هذا الفيروس وهذا المرض الموض

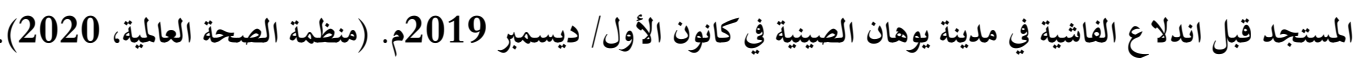




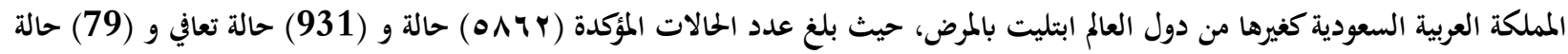

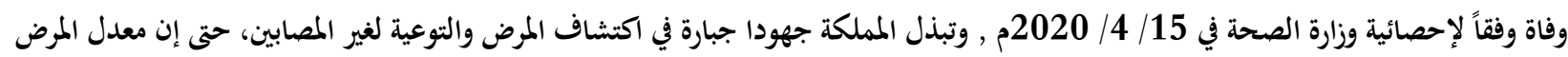

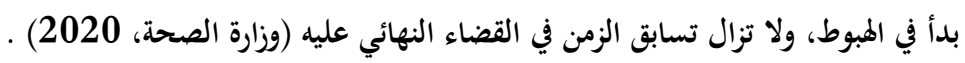

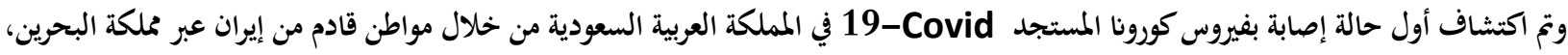
يوم الاثنين 2 مارس 2020 (العبية.نت، 2020) ، ومنذ ذلك الوقت بدأت حالات الإصابة تزداد وبدأ ناقوس الخطر يدق.

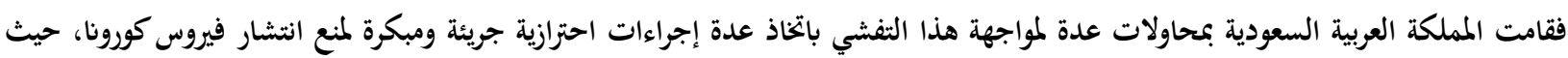

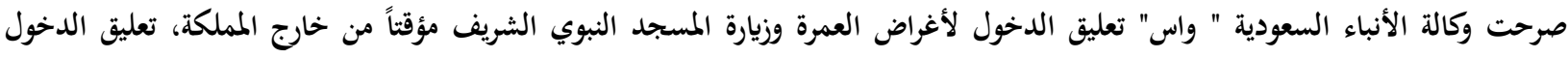

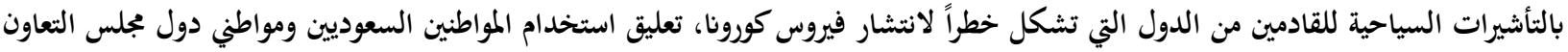

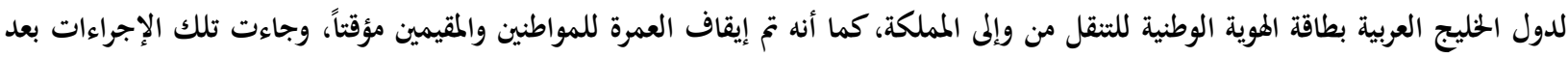

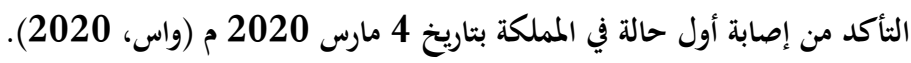

استمرت المملكة وسعت جاهدة في الحد من تفشي فيروس كورونا المستجد وحرصاً من حكومة المملكة الرشيدة على مواطنيها كافة وعلى أبنائها وبناتما

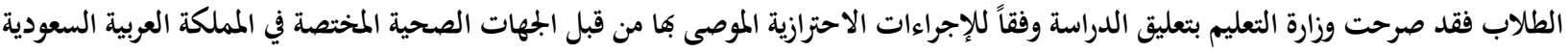

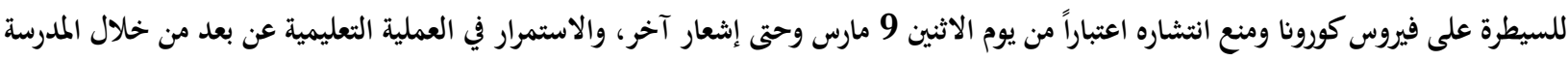
والجامعة الافتراضية (واس، 2020).

ولم يكن التعليق للطلاب والطالبات فقط بل امتد ليشمل جميع المواطنين فقد صرحت وزارة الداخلية بتعليق الحضور للعمل في كافة الجهات الحكومية

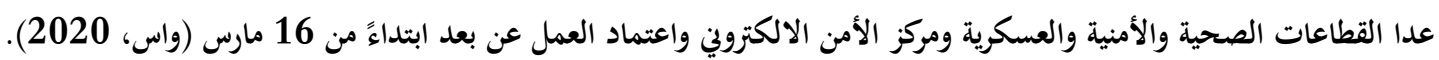

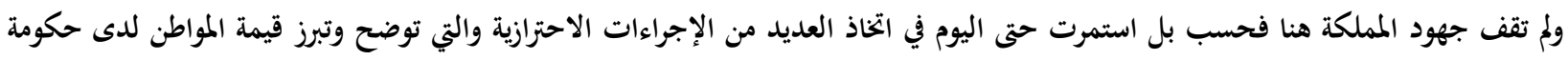

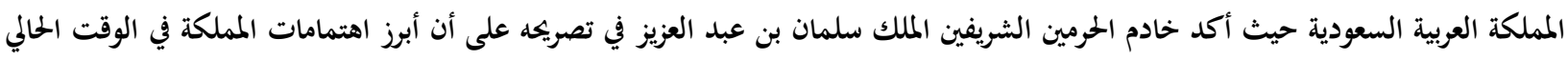

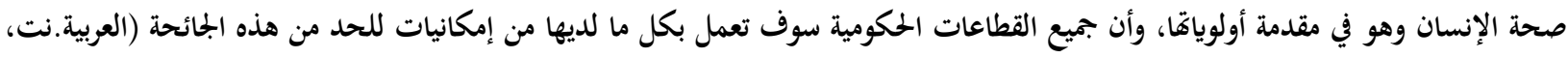

ومما أكد على جعل الدولة صحة الإنسان في مقدمة أولوياتما أمر خادم الحرمين الشريفين بتقديم العلاج مجانا للمواطنين والمقيمين ومخالفي الإقامة ( تويتر واس العام) .

وتلك القرارات تبعث في نفس المواطن والمقيم الاطمئنان والراحة لشعوره باهتمام الدولة به في ظل الظروف الراهنة. وواصلت المملكة في اتخاذ

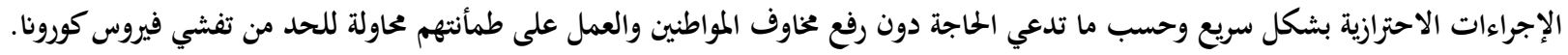
ولم تقف المملكة على اتخاذ الإجراءات الاحترازية في نطاق ضيق بل اتسع نطاقها فدعت لعقد قمة استثنائية افتراضية لقادة بجموعة العشرين للحد من

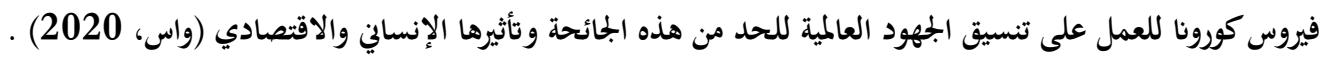

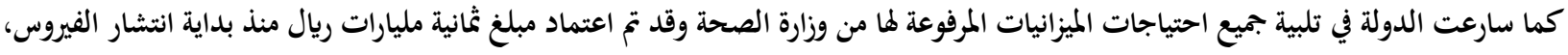

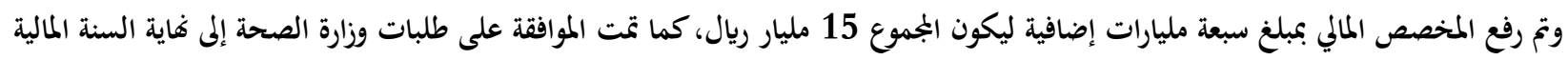
بنحو 32 مليار ريال أخرى (واس، 2020). 
وتم إطلاق منصة وطنية لتمكين الراغبين في التطوع الصحي بالجمالات الصحية المباشرة والغير مباشرة في التاسع من أبريل وقد استقبلت أكثر من 79

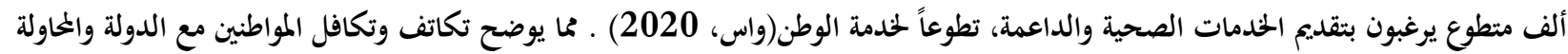
من قبل الجميع للعمل على الحد من تلك الجائحة

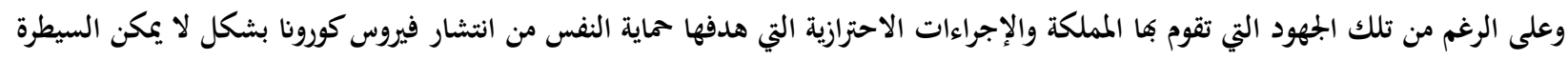

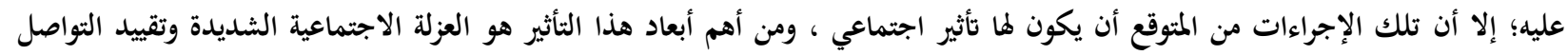

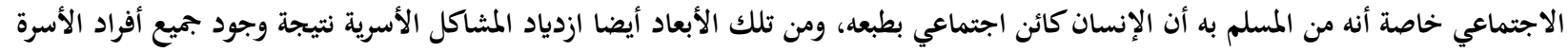

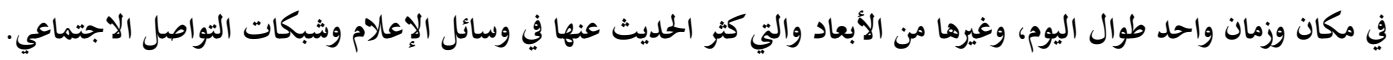

وقد أشارت دراسة (مركز الدراسات الإستراتيجية بالجحمعة الأردنية،2020) والتي أشارت إلى شعور (64\%) من الأردنيين بالقلق الاجتماعي

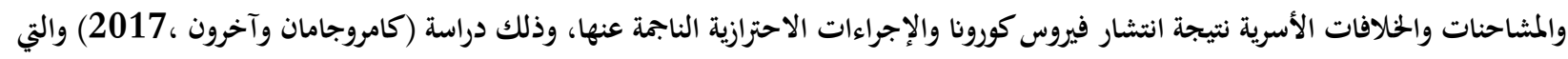

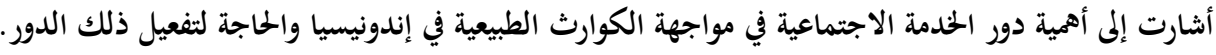

وفي سياق الدراسات السابقة التي أشارت إلى الآثار الاجتماعية الناجمة عن الكوارث والأزمات الصحية يجب دراستها بشكل متعمق، تظهر الفجوة

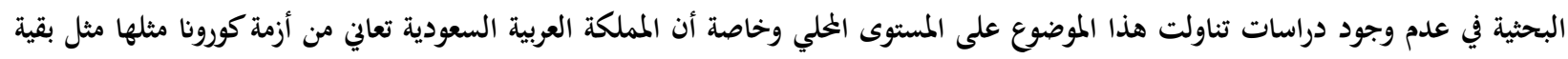
دول العالم.

وفي ضوء عدم وجود دراسات تناولت الآثار الاجتماعية المثترتبة على جائحة كورونا يسعى هذا البحث لتحديد الآثار المترتبة على هذه الجائحة ومدى

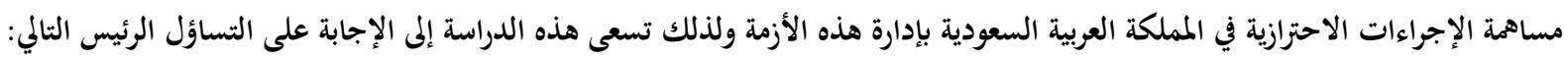
ما الآثار الاجتماعية المترتبة على الإجراءات الاحترازية لإدارة جائحة كورونا في المملكة العربية السعودية؟

أهمية الدراسة:

الأهمية النظرية:

1. في ضوء التطور لجائحة كورونا عالميًا ظهرت الحاجة العلمية لمثل هذه النوعية من الدراسات للتشديد على أهمية ترابط القطاعات الاجتماعية المختلفة

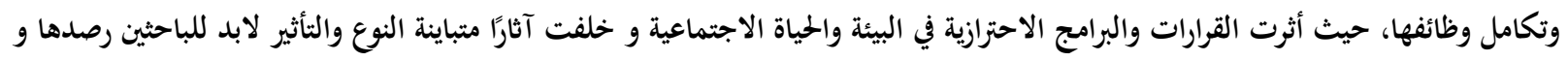
البحث فيها. إثراء المكتبة البحثية بدراسات توثق واقع خطط الطوارئ في المملكة العربية السعودية و فن إدارتها للأزمات محليًا و صدى هذا الأمر على مستوى .2 العالم.

الأهمية التطبيقية:

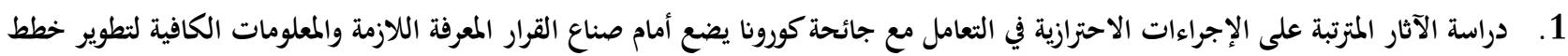
الطوارئ و الثدابير الاحترازية الجائحة كورونا خصوصًا و أي أزمات مستقبلية عمومًا. 2. ستوفر هذه الدراسة نتائج قد يُعتمد عليها كأساس علمي ينطلق منه الباحثين لبحث قضايا أخرى تربط العلوم الاجتماعية وتحديدًا الخدمة الاجتماعية

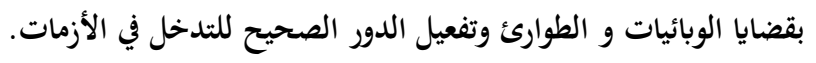


1 .

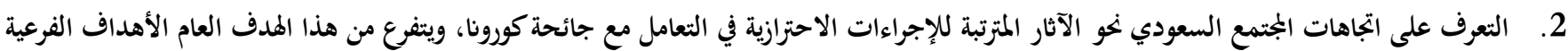

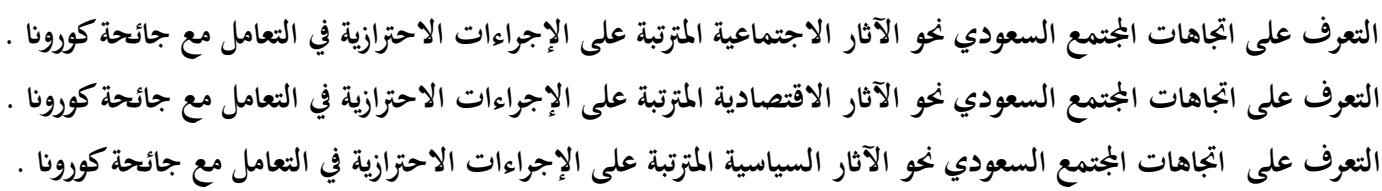

تساؤلات الدراسة:

1. ما اتجاهات الججتمع السعودي نحو الإجراءات الاحترازية في التعامل مع جائحة كورونا في المملكة العربية السعودية؟ 2. ما اتجاهات الججتمع السعودي نحو الآثار المترتبة للإجراءات الاحترازية في التعامل مع جائحة كورونا؟

$$
\text { ويندرج تحت هذا التساؤل العام عدة تساؤلات فرعية: }
$$

ما اتجاهات الججتمع السعودي نحو الآثار الاجتماعية المترتبة على الإجراءات الاحترازية في التعامل مع جائحة كورونا؟

ما اتجاهات المجتمع السعودي نحو الآثار الاقتصادية المترتبة على الإجراءات الاحترازية في التعامل مع جائحة كورونا؟

ما اتجاهات الجتمع السعودي نحو الآثار السياسية المترتبة على الإجراءات الاحترازية في التعامل مع جائحة كورونا؟

\section{مفاهيم الدراسة:}

\section{الإجراءات الاحترازية Precautionary measures:}

حسب المعجم الوسيط ف الاحتراز من احتزز منه أي توقاه، ويُعرف اصطلاحًا على أنه:"ججموعة الإجراءات التي من شأفا أن تكون حافظة وواقية من وقوع أمر مخالف في النظام" (المهلا، 2016).

ويقصد بها في هذه الدراسة هي تلك الجهود التي بذلتها المملكة العبية السعودية من إجراءات أمنية واقتصادية واجتماعية احترازاً لحماية الشعب من تفشي وباء كورونا.

\section{إدارة أزمة Crisis management}

ويستعاض هنا بهذا المصطلح كبديل عن إدارة جائحة، والجائحة في المعجم الوسيط هي: المُّصيبة تحل بالرجل في ماله و تجناحه كله.

أما اصطلاحًا فو إدارة الأزمات تعني:"العملية الإدارية المستمرة التي تتم بالتنبؤ بالأزمات الختملة عن طريق الاستشعار ورصد المتغيرات الداخلية والخارجية المولدة للأزمات وتعبئة الموارد والإمكانات المتاحة لمنع أو الإعداد للتعامل مع الأزمات بأكبر قدر ممكن من الكمات الكفاءة والفاعلية وبما يحقق أقل

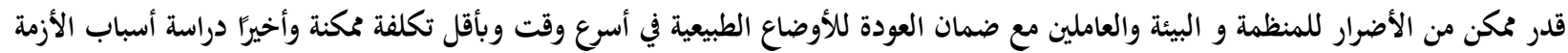

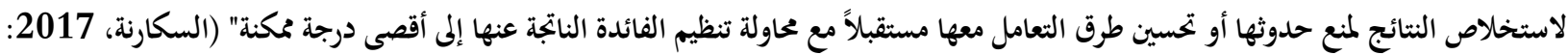

أما إجرائيا : فما ترمي به هذه الدراسة في إدارة الأزمة هو : تلك القرارات التي تتحكم بمنع تفشي الوباء،من قرارات مهمة وفعالة للسيطرة على الموقف والحد من انتشار الجائحة أكثر. 


\section{فيروس كورونا Coronavirus disease COVID-19:}

يُشير إلى مجموعة من الفيروسات التي لديها القدرة على التحور واكتساب جينات من فيروسات أخرى و تصيب الإنسان والحيوان.

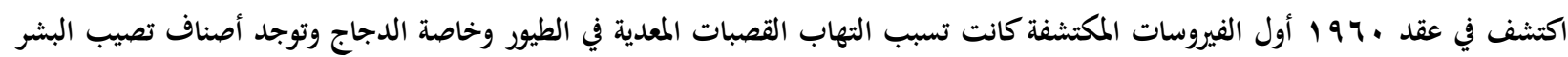

$$
\text { أولاً: مرضن تلخيصها كالآتي: }
$$

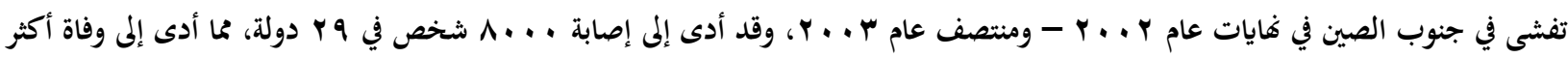

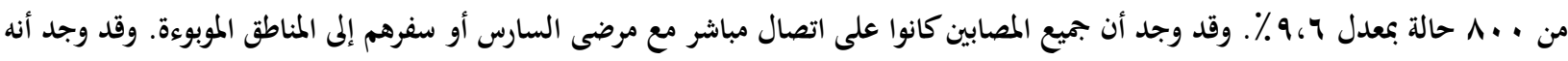

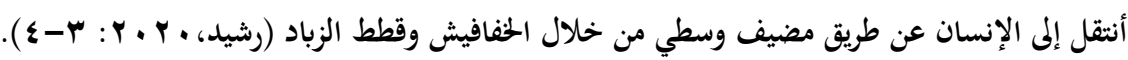

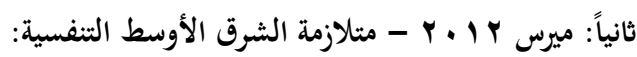

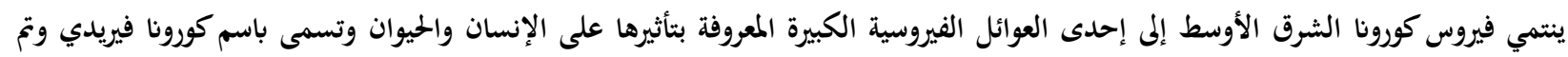

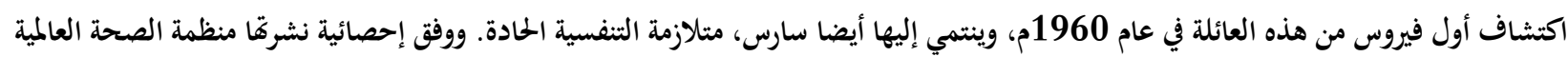

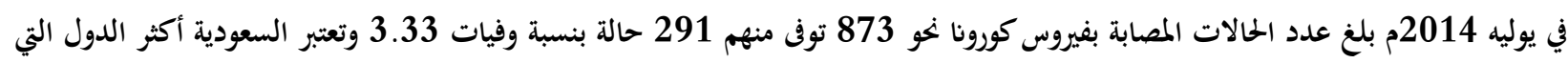

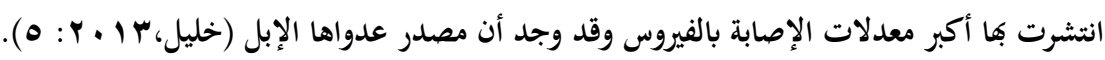
ثالثاً: الشكل الجديد لـ كورونا المستجد: فيروس كورونا المستجد (كوفيد-19) من سلالة كورونا، تم التعرف عليه لأول مرة في عدد من المصابين باعراض الالتهاب الرئوي في مدينة ووهاب الماندان

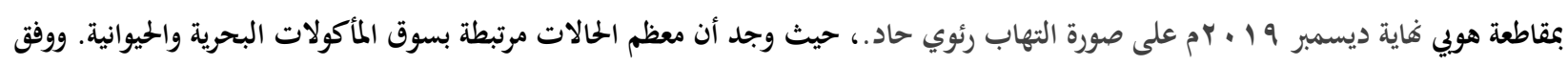

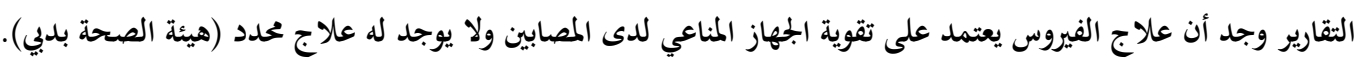

طرق انتقال الفيروس والإصابة به: بسبب عدم توفر المزيد من المعلومات عن خصائص الفيروس، فإن الأطباء يرجحون أن فيروس كورونا ينتقل كباقي الأمراض المعدية الأخرى عبر: الانتقال المباشر من خلال الرذاذ المتطاير من المريض أثناء الكحة أو العطس.

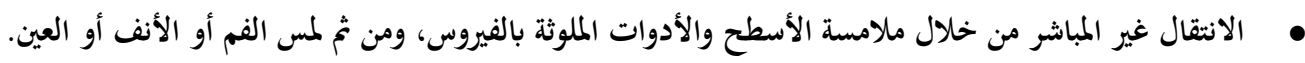
المخالطة المباشرة للمصابين (الصحة، 2020). 


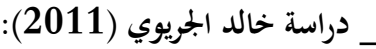

بعنوان " إدارة الأزمات والكوارث البيئية: دراسة تطبيقية على المملكة العربية السعودية" وهدفت إلى دراسة وتحليل المفاهيم النظرية والأساليب الإدارية الحديثة ذات الصلة بالأزمات وأنواعها وفي كل مراحلها في المملكة العربية السعودية، وتوظيف التقنية الحديثة لدرء أخطار الكوارث والأزمات والاستفادة من الدراسات والبحوث العلمية في هذا الجحال، متابعة أداء الأجهزة العاملة في مجال درء الأزمات ومقارنة أنشطتها في كل مرحلة بالأنشطة الإدارية الأخرى للاستفادة من تجاربها، نشر الوعي البيئي وثقافة الأزمات والكوارث بين أفراد الجتمع السعودي، دراسة وتحليل المصاعب والمعوقات التي يمكن أن تواجه إدارة الأزمات وأثر تلك المعوقات على نتائج الأزمات ودورها

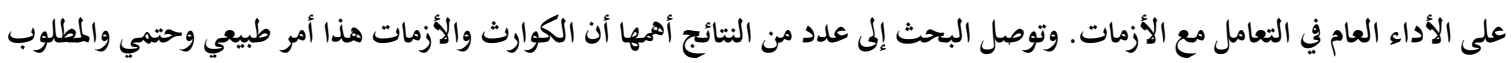
كيفية ججاكتها بأشياء علمية ومتعددة الحدث من منطقة لأخرى علما بان هنالك مناطق أسباها تتدخل في تفاقم المشكلة وبذلك يظهر الدور الإنساني والجهود البشرية جليا والثدافع الدولي والمشاركة الجماهيرية وإبراز عنصر الشباب بالتدريب بأحدث الأساليب العلمية في إعادة البيئة إلى وجهها الطبيعي بالسرعة المطلوبة وإثراء البحوث في الجحال الإنساني والبشري وعوامل الإسعاف الأولي والبحوث العلمية لمنتجات تقنية تعيد الحياة إلى دورتا الطبيعية.

يتضح هنا أهمية البحث العلمي وتكثيف الدراسات في مجال خطط الطوارئ والأزمات ودور التقنية في رفع جودة معايير هذه الحطط وتسهيل تنفيذها بطرق إبداعية وسريعة ومنظمة. _دراسة قاسمي وسلطاني (2015):

بعنوان "دور شبكات التواصل الاجتماعي في التوعية الصحية حول مرض الإيبولا: الصفحات الفيسبوكية نموذجا"، هدفت الدراسة إلى: الكشف عن دور شبكات التواصل الاجتماعي وتحديدًا شبكة الفيسبوك من خلال صفحة (2015 Ebola)، وكانت دراسة استكشافية وقد لجأت الباحثتان للمنهج الوصفي التحليلي للوصول للنتائج ، و على الاستبانة و الملاحظة بالمشاركة كأدوات لجمع البيانات من المبحوثين، و أظهرت النتائج الدور الفعال لشبكات التواصل الاجتماعي حيث سجلت صفحة (2015 Ebola) نسب مشاركة عالية وتنامي متزايد في المثتابعة و أوعزت الباحثتان السبب في ذلك إلى دافع التوعية الصحية بخطورة هذا المرض وانتشاره، الأمر الذي أدى إلى تحقيق أفراد العينة لمستوى عالي من الإشباع الثقافي الصحي بواسطة منشورات الصفحة مما ترك أثر إيجابي عليهم. مما يؤكد أهمية وسائل التواصل الاجتماعي وأدوات الإعلام الجديد كسلاح ذو حدين في تحريك الجتمع والتأثير على درجة ونوعية وعيه بالقضايا والاهتمامات.

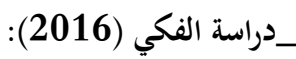

بعنوان " الثقافة الجختمعية ومعدلات الإصابة بالأمراض في أفريقيا (الايبولا: ليبيريا- الايدز: إثيوبيا- السحائي: بوركينافاسو)"، وذلك بغرض معرفة أثر العامل الثقافي على الأمراض من خلال العادات والتقاليد السائدة في تلك الجتمعات، دمج الباحث ما بين المنهج الوصفي و دراسة الحالة، واستعان بالمقابلة الفردية والجماعية كأدوات لجمع البيانات مع مواطني تلك الدول بلإضافة للوثائق الأولوية والثانوية،

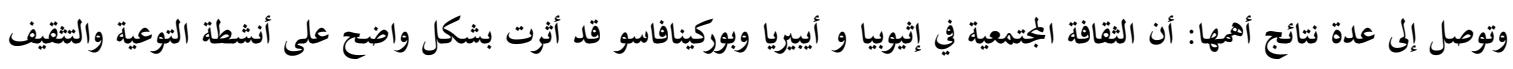


الصحية، و أن انعدام المعلومات التثقيفية بشكل رسمي ساعد في انتشار مرض الإيبولا في المراحل الأولى حيث لعبت الإشاعة كبير في انتشاره وسط الجتمع، ضعف الاقتصاد والبنيات التحتية للنظام الصحي (أثيوبيا و أيبيريا وبوركينافاسو) كان عاملاً أساسياً في ارتفاع عدد الحلالات المصابة والوفيات بالأمراض، التعاون بين حكومات تلك الدول ومنظمة الصحة العالمية ودعم الدول الأوروبية ساعدوا في توفير بيئة صحية جيدة للرعاية الصحية في الحد من تلك الأمراض، وتوصلت الدراسة إلى عدة توصيات أهمها:

- العمل على التنمية الشاملة وبالذات في البحال الصحي في أفريقيا بتوفير الرعاية الصحية الأولية. - ضرورة استنهاض مشاركة القوى الاجتماعية الفاعلة في الجتمع في التصدي للأمراض. - على المؤسسات الصحية والكوادر الطبية تفهم ثقافة البجتمع تجاه المرض. تبرز في هذه الدراسة أهمية الحلفية المرجعية الثقافية ودور الإشاعات في اتساع الأزمات وتفاقم سلبياتا وهو ما لم يحدث في السعودية بسبب وعي وانضباط الجنمع والتوعية الصحية المكثفة.

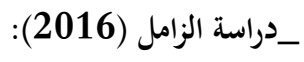

بعنوان "التخطيط لمواجهة الأزمات والكوارث في المملكة العربية السعودية " دراسة مطبقة على المسئولين والخبراء في الجهات ذات العلاقة بالأزمات والكوارث) تعد الأزمات والكوارث مشكلة تواجه كثيراً من الدول ومن بينها المملكة العربية السعودية، وتمدف الدراسة إلى لم التخطيط لمواجهة الأزمات والكوارث من خلال التعرف إلى واقع مواجهة الكوارث والأزمات في المملكة العربية السعودية، وتقديم تصور مقتح للإنشاء جهة تعنى بمواجهة الأزمات والكوارث، واعتمدت الدراسة منهج المسح الاجتماعي، وطبقت على المسئولين والحبراء في الجهات التي تعنى بمواجهة الأزمات والكوارث في مدينتي الرياض وجدة، وأظهرت النتائج ضعف التخطيط في هذه المؤسسات، وكذلك كانت النتيجة المتعلقة بالتنسيق بين المؤسسات حيث بلغ الوزن النسبي للموافقة 70\% و وتعد هذه النتيجة ضعيفة لتعلق الموضوع بالأزمات

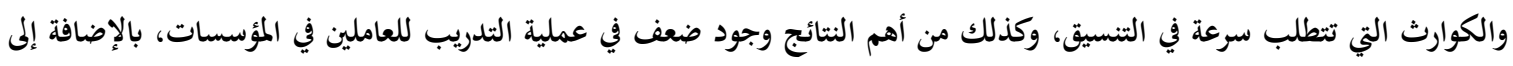
بروز حاجة إلى إنشاء جهة موحدة تعنى بمواجهة الأزمات والكوارث، وقدمت الدراسة في التوصيات تصور مقتح لجهاز يعني بمواجهة الأزمات والكوارث في المملكة العربية السعودية.

ترتبط نتائج هذه الدراسة بوجوب الالنفات لفن إدارة الأزمات في المملكة العربية السعودية وهو ما عبرت عنه الباحثات في أهمية الدراسة.

$$
\text { _دراسة الهاثمي (2017): }
$$

بعنوان "دور القوانين والتشريعات الدولية والخلية في مواجهة أزمات الكوارث" هدفت الدراسة إلى تحليل دور القوانين والتشريعات الدولية والوطنية في الحدد من الكوارث والأزمات، وذلك من خلال توضيح دور تلك التشريعات على المستوى الدولي والوطني، وما أحرزته الدول والجتمع الدولي والمنظمات الدولية في وضع وسن تلك القوانين، والوقوف على مدى تناسب قوانين وقواعد ومبادئ الاستجابة الدولية في حالات الكوارث والمخاطر والتعرف على الفجوات التي يسدها التشريع في أنشطة وأعمال الحد من مخاطر الكوارث. استخدم الباحث المنهج التاريخي الوصفي التحليلي، من خلال تحليل العناصر الموضوعية والقانونية، المتعلقة بموضوع الدراسة، على اعتباره المنهج المناسب لبحث هذه المثكلة. وفي غاية المطاف قدم الباحث نتائج الدراسة والتي تمثلت في الآتي: حظيت الكوارث باهتمام دولي لعدم اعترافها بالحدود الدولية. كما أن القوانين والتشريعات الخاصة بالكوارث لم تلقى النصيب الوافي من البحث والدراسة، يكمن الدافع لاستحداث 
قوانين جديدة للاستجابة للكوارث في الثغرات الموجودة في نطاق القانون الدولي القائم، كما وتضمنت الاتفاقيات والمعاهدات الدولية

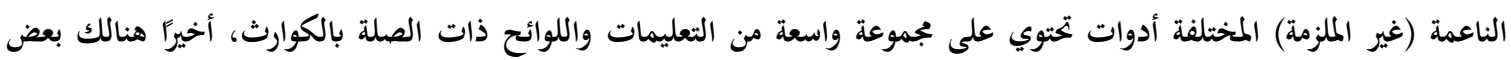
المعاهدات المحددة التي وإن كانت بحد ذاتحا غير ملزمة فهي تترك على أقل تقدير أثرًا سياسيًا واضحًا في حالة الاستجابة لمخاطر الكوارث. تؤكد نتائج هذه الدراسة على أهمية التخطيط للطوارئ وسن القوانين والتشريعات لذلك وهي ما تتفق مع الأهمية النظرية للبحث.

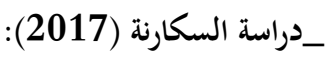
بعنوان" خطط الطوارئ ودورها في مواجهة الأزمات" تمدف إلى إلقاء الضوء على مدى أهمية خطط الطوارئ في مواجهة الأزمات وذلك من أجل تقليل المخاطر والخسائر المترتبة عليه، أهم النتائج التي توصلت إليها هذه الدراسة: - أن خطط الطوارئ لها دور بارز ومهم في مواجهة الأزمات والكوارث. - على منظمات الأعمال أن تقوم بوضع خطة متكاملة ومعد مسبقا لمواجهة الأزمات وإمكانية السيطرة عليها من خلال تحضير وتدريب العاملين لديها على كيفية مواجهة هذه الأزمات. -وجود غرفة عمليات لإدامة العمل بعد وقوع الأزمات يعتبر من المستلزمات الأساسية لنجاح إدارة الأزمات. - وضع كافة التزتيبات اللازمة وتوضيح المهام المطلوبة من العاملين في حالة وقوع الأزمات.

وأوصت الدراسة منظمات الأعمال بوضع خطط واستراتيجيات مناسبة لمعالجة الأزمات حال وقوعها، كما يجب عليها أن تقوم بتدريب الموظفين لديها على كيفية مواجهة الأزمات من خلال تطبيقات وتمارين عملية تساعدها في الاستفادة منها في حالة وقوع الأزمات. تتماشى النتائج هنا مع التخطيط المبكر للجائحة قبل دخولها للسعودية، وعلى أهمية فرض الإجراءات الاحترازية للحد من الآثار السلبية لأي أزمة. _دراسة مركز الدراسات الإستراتيجية بالجامعة الأردنية (2020):

بعنوان "نظرة الأردنيين وتعاملهم مع فيروس كورونا "وتمدف الدراسة إلى التعرف على الآثار الاقتصادية والاجتماعية والنفسية لفيرو كورونا على الأردنيين، على عينة ممثلة للمجتمع الأرددي من كافة الخحافظات، وتوصلت الدراسة إلى مجموعة من النتائج وهي: تعتقد الغالبية العظمى من الأردنيين (73\%) أن إجراءات الحكومة الاقتصادية (صرف الرواتب، تأجيل أقساط البنوك، تخفيض الفائدة على القروض، ..) ستساهم والى درجة كبيرة في التخفيف عن المواطنين في هذه الأزمة، وأن أزمة فيروس كورونا تصيب (66\%) من الأردنيين بالقلق والتوتر النفسي، وحظر التجول يتسبب بالقلق

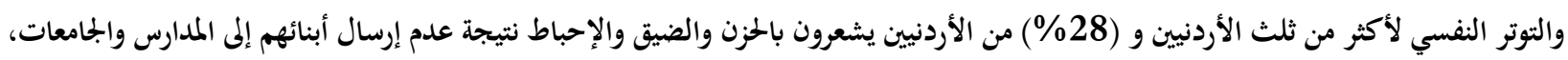
كما أن (89\%) من الأردنيين يشعرون بالحزن والإحباط نتيجة رؤية المساجد والكنائس مغلقة. و (64\%) من الأردنيين يرون أن الاستمرار في فرض حظر التجول وتعطيل القطاعين العام والخاص سوف يؤدي إلى مشاحنات وخلافات أسرية وتبعات نفسية وصحية سلبية. من نتائج هذه الدراسة يتضح لنا أن انتقال قطاعات الدولة في السعودية للتقنية الحديثة كان في صالح البجتمع، سواء في التعليم أو العمل الحكومي والخاص. 
أكدت الدراسات السابقة على أهمية التخطيط للطوارئ بالاعتماد على التقنية الحديثة و بتدريب الموظفين والعاملين، كما أفها دلت على وجوب عدم المات

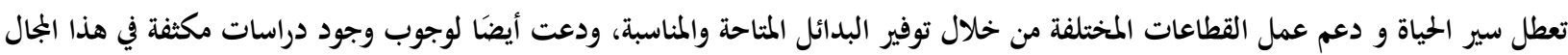
و اعتراف دولي أكبر به من خلال سن قوانين وتشريعات رسمية.

استفادت الدراسة الحالية من الدراسات السابقة من ناحية الجانب النظري والنتائج في صياغة مشكلة الدراسة، و اتفقت الدراسة الحالية مع الدراسات

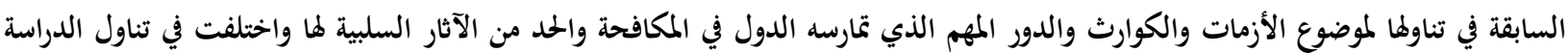
لموضوع الآثار الاجتماعية المترتبة على الإجراءات الاحترازية لجائحة كورونا في المملكة العربية السعودية.

اتفقت الدراسة الحالية مع دراسة مركز الدراسات الإستراتيجية بالجامعة الأردنية (2020) في التعرف على الآثار الاجتماعية والاقتصادية الناتجة عن جانخة كورونا. أما دراسة الجريوي (2011) فقد تماشت نتائجها مع ضرورة توظيف التقنية الحديثة لمواجهة الكوارث والأزمات بالإضافة إلى ضرورة الالتزام بالإجراءات الاحترازية التي التخذتما الدولة لمواجهة الأزمات والكوارث.

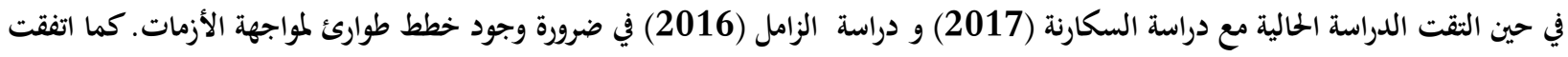

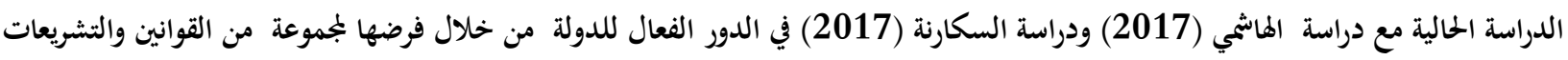
التي تساهم في الحد من الآثار السلبية للكوارث والأزمات.

أما دراسة قاسي وسلطاني (2015) فترتبط مع الدراسة الحالية في أهمية مساهمة مواقع التواصل الاجتماعي في نشر ورفع الوعي الصحي للأفراد. أخيرًا فإن الدراسة الحالية اتفقت مع دراسة الفكي (2016) في أهمية الوعي والثثقيف الصحي في الحد من انتشار المرض والتقليل من آثاره السلبية

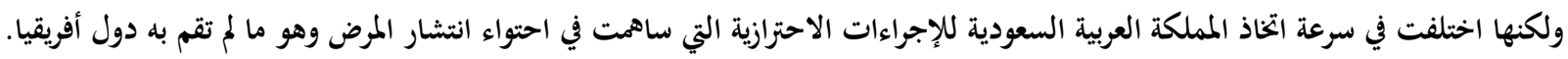
أدبيات الدراسة:

:Crisis Management إدارة الأزمات "نشأ اصطلاح إدارة الأزمات في الأصل من خلال علم الإدارة العامة وذلك للإشارة إلى دور الدولة في مواجهة الكوارث المفاجئة والظروف الطارئة

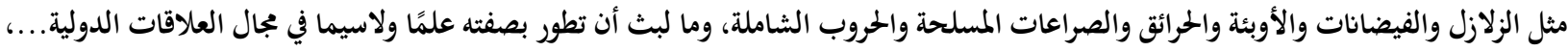

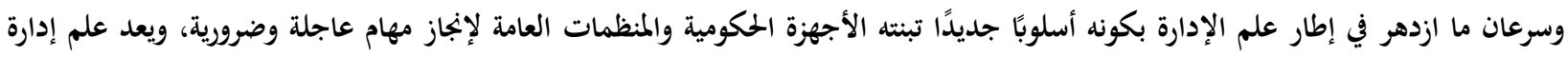

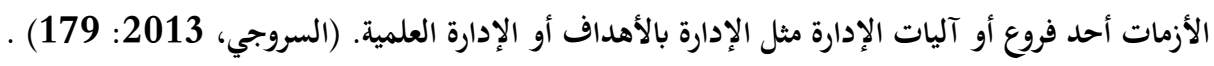
الفرضيات التي يقوم عليها نموذج التدخل في الأزمات: الأولى: تعرض نسق التعامل للأزمة يؤدي إلى اختلال توازنه ومع ذلك فإن حالة الأزمة ليست مرضًا ولكنها تعبّر عن مواقف صراعات مبكرة لم تحل أو تم حلها جزئيًا. الثانية: أثناء تعرض نسق التعامل للأزمات قد يدرك موقف الأزمة باعتباره تمديدًا لاحتياجاته الغريزية أو لإحساسه بالفقد والحسارة وهذا الإدراك يرتبط بمجموعة من الانفعالات التي تعتمد على السمات الشخصية للنسق حيث يصبح في حالة من الاضطراب والحساسية الشديدة والقابلية السريعة للتأثر وتظهر عليه أعراض القلق والاكتئاب والتوتر. 
الثالثة: أثناء الأزمة تضعف الميكانيزمات الدفاعية للذات فتصبح أكثر قابلية للتغيير والتأثيرات الخارجية، فيصبح الشخص أكثر استعدادًا لقبول

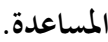

الرابعة: خلال مرحلة إعادة التوازن تنشأ وتتطور أساليب معدلة جديدة يمكن أن تسهم بدرجة كبيرة في التعامل مع المواقف وتعمل هذه الأساليب

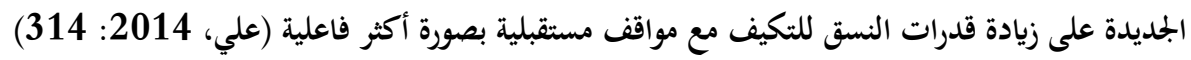

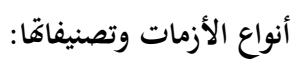

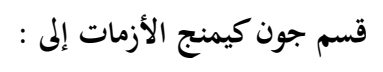

$$
\begin{aligned}
& \text { 1 } 1 \text { أزمات بيولوجية: وهي تلك الأزمات التي تتضمن الأمراض الخطيرة. }
\end{aligned}
$$

2. أزمات بيئية: التهجير وفقدان الوظيفة أو إخلاء السكن أو تغيير المهنة أو الحرائق أو الفيضانات أو الزلازل أو السيول (رشوان والقرني،

. (126-125:2013

إن أزمة انتشار فيروس كورونا أزمة بيولوجية، تتمثل خطورتما في الانتشار السريع للعدوى من هذا الفيروس، وأنه قد يؤدي إلى التهاب رئوي حاد لدى بعض كبار السن ممن تضعف مناعتهم والمصابين أيضًا بالأمراض المزمنة، وهناك حالات منهم تنتهي بالوفاة.

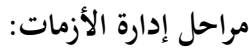

يُعد نموذج بيرسون و متروف من أشهر النماذج و أوضح الباحثان أن إدارة الأزمات تتم في خمس مراحل تمر وهي: 1. مرحلة اكتشاف إشارات الإنذار المبكرة: وتتحدد هذه المرحلة بانتشار الوباء في العالم وحتمية وصوله إلى المملكة العبية السعودية كونها أحد

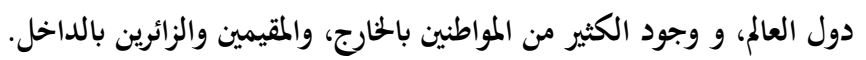

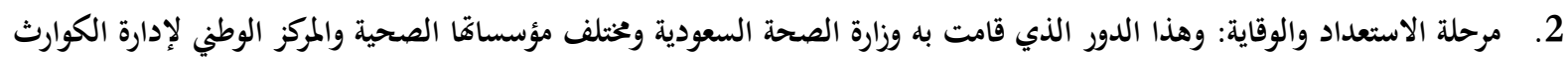

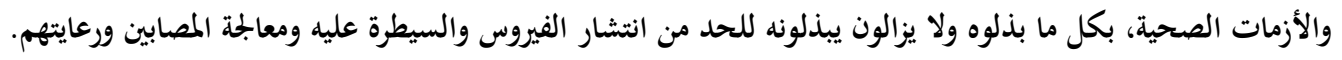

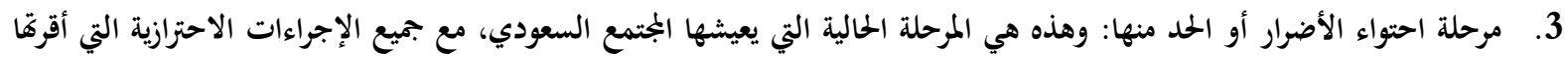

$$
\text { الدولة ونفذها الجهات والأفراد، لمنع تفشي الفيروس وانتشاء النشاره. }
$$

4. مرحلة استعادة النشاط: ويتم ذلك عن طريق تنفيذ برامج قصيرة وطويلة الأجل حتى يمكن أن يستأنف الجتمع نشاطه وسير حياته الطبيعية

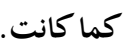
5. مرحلة التعلم: وتتضمن استرجاع ودراسة الأحداث التي وقعت واستخلاص الدروس المستفادة منها. ( الدسوقي: 2013: 42 -48) 


\section{$\underline{\text { Precautionary measures : الإجراءات الاحترازية }}$}

يواجه العالم حاليا تطورات متسارعة تتعلق بتفشي فيروس كورونا المستجد (كوفيد - 19)، وتسعى الدول ومن ضمنها المملكة العربية السعودية

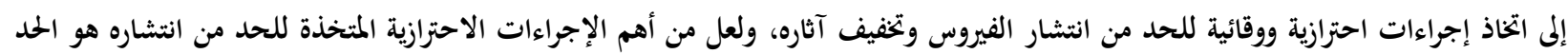
من المخالطة والتجمعات المثقاربة بين الناس إلى أقصى درجة بما في ذلك وقف الاجتماعات والاختلاط في أماكن العمل والتسوق.

وتأسيساً على ما توصلت إليه الأوضاع القائمة حرصت حكومة المملكة على تطبيق المعايير الدولية المعتمدة، ودعم جهود الدول والمنظمات الدولية وبالأخص (منظمة الصحة العالمية) لوقف انتشار الفيروس ومحاصرته والقضاء عليه، بإذن الله.

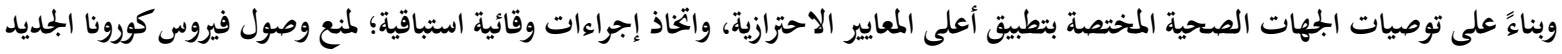
(COVID-19)

$$
\text { 1 }
$$

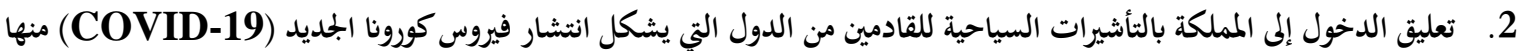

خطرًا، وفق المعايير التي تحددها الجهات الصحية المختصة بالمملكة. 3. تعليق استخدام المواطنين السعوديين، ومواطني دول مجلس التعاون لدول الحليج العربية، بطاقة الهوية الوطنية؛ للتنقل من وإلى المملكة، ويستثن من ذلك السعوديون الموجودون في الخارج في حال كان خروجهم من المملكة ببطاقة الهوية الوطنية، ومواطنو دول مجلس التعاون

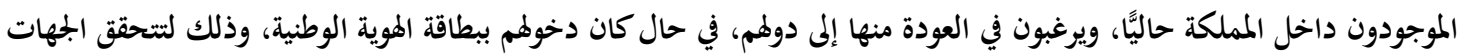

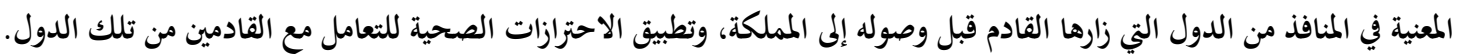
4. تعليق الحضور لمقرات العمل في جميع القطاعات الحكومية والخاصة، عدا القطاعات المستثناة. 5. ت تعليق رحلات الطيران الداخلية ونشاط الحافلات وسيارات الأجرة والقطارات. 6. تعليق الرحلات الجوية الدولية إلا في الحالات الاستثنائية. 7. 8. 9. إيقاف الصلاة في جميع المساجد والاكتفاء برفع الأذان.

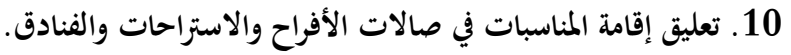
11. تعليق جميع الأنشطة والمسابقات الرياضية.

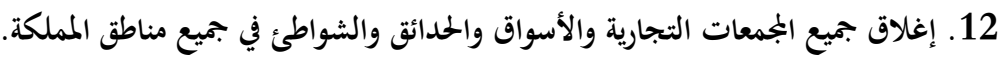

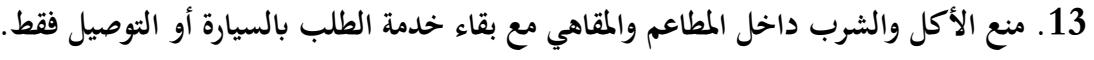

14. إغلاق الصالونات الرجالية والمثاغل النسائية.

15. إيقاف تصدير الأدوية والمستحضرات الصيدلانية والأجهزة الطبية.

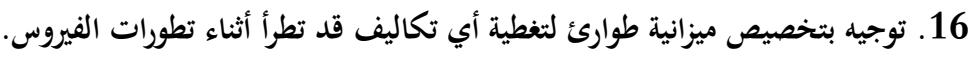

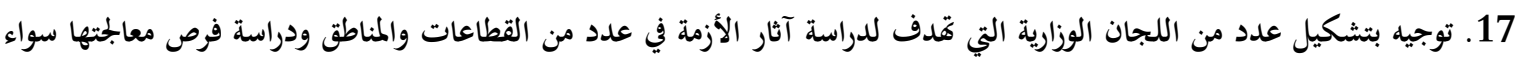
بالدعم أو التحفيز أو غيرهما. 18. تأجيل تنفيذ إجواءات إيقاف الحذدات والحجز على الأموال من قبل الميئة العامة للزكاة والدخل ووضع المعايير اللازمة لتمديد فترة التأجيل للأنشطة الأكثر تأثراً حسب الحاجة. 19. إصدار نموذج تصريح للتنقل خلال فترة منع التجول من موقع وزارة الداخلية. (أخبار السعودية الإلكترونية، 2020) 


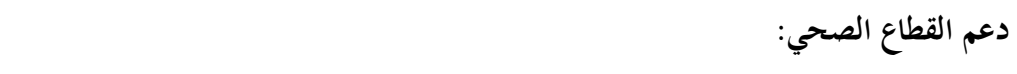

$$
\begin{aligned}
& \text { 1 } 1 \\
& \text { 2. }
\end{aligned}
$$

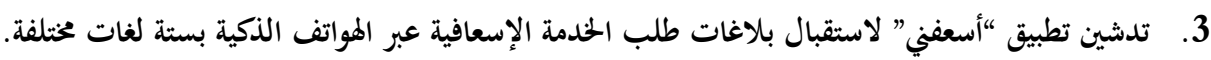

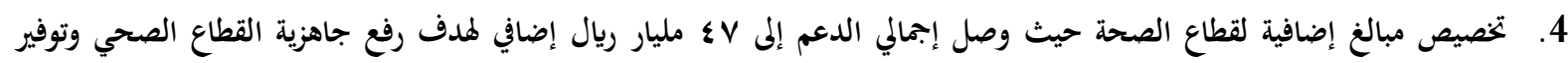

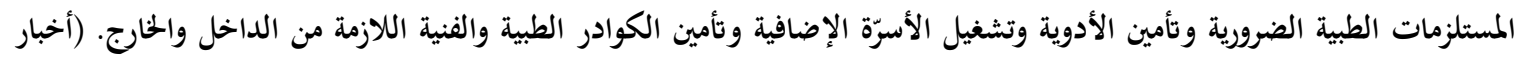

السعودية الإلكترونية، 2020)

دعم القطاع الخاص : (n)

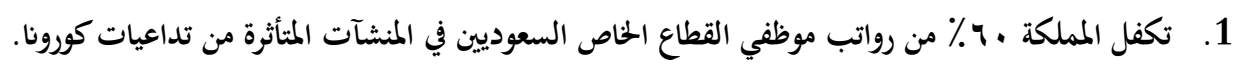

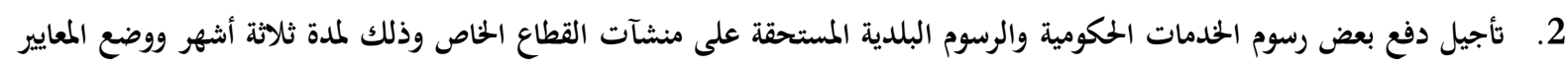

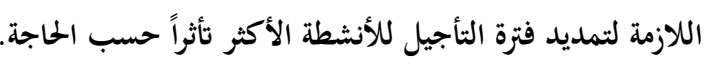
3. 4.

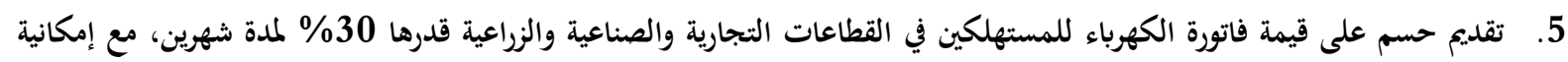
التمديد إذا استدعت الحاجة.

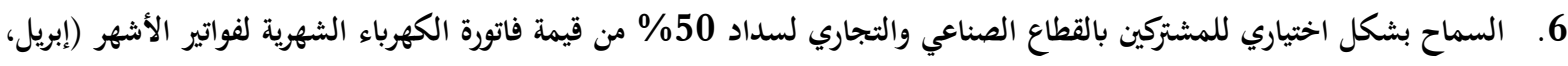

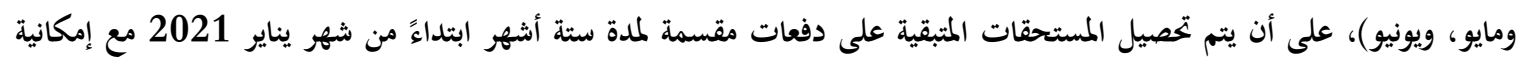
تأجيل فترة السداد إن استدعت الحاجية. 7. دعم الأفراد العاملين بشكل مباشر والذين ليسوا تحت مظلة أي شركة ومسجلين لدى الهيئة العامة للنقل في أنشطة نقل الركاب وتم إيقافهم

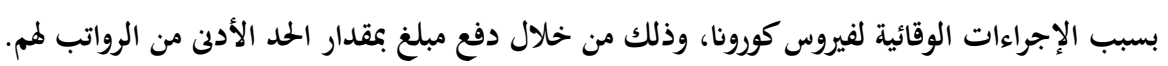

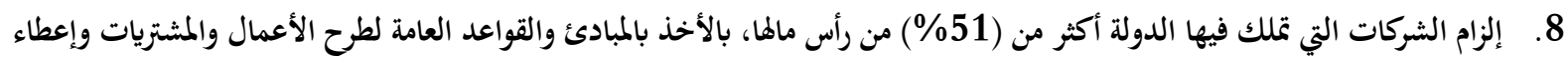

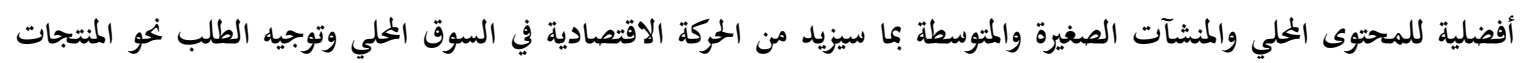
والخدمات الخلية. (أخبار السعودية الإلكترونية، 2020) دعم الحذدات الإنسانية : 1 2. 3. دعم تنمية الموارد البشرية السعوديين والسعوديات العاملين في خدمة التوصيل من خلال التطبيقات بدعم شهري يصل إلى بـ آلاف ريال. 4. تدشين وزارة العمل والتنمية الاجتماعية منصة "العمل التطوعي" وذلك تفعيلاً للدور التطوعي في خدمة وتنمية الجنمع بحيث تتيح

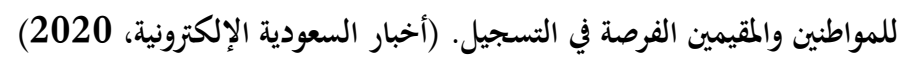


مبادرات لتحفيز القطاع الخاص :

وزارة الشؤون البلدية والقروية

تأجيل تحصيل رسوم الخدمات البلدية المستحقة على القطاع الخاص لمدة ب أشهر لأكثر من . ـ ا نشاط اقتصادي. وزارة التجارة

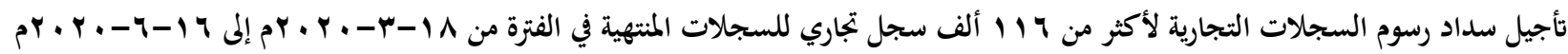
لمدة • 9 يوماً من تاريخ انتهاء السجل.

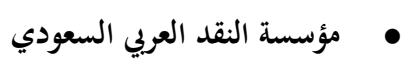

برنامج تصل قيمته إلى •ه مليار ريال يستهدف دعم القطاع الخاص وتكينه من القيام بدورة في تعزيز النمو الاقتصادي. • • صندوق تنمية الموارد البشرية (هدف)

تخصيص r.ه مليار ريال لدعم منشآت القطاع الخاص لتوظيف وتدريب السعوديين ضمن مبادرة الدعم الحكومي لتمكين المنشآت وتنمية أدائها.

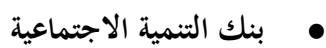

دعم بقيمة r ا مليار ريال لمساندة المواطنين والأسر والمنشآت الناشئة والصغيرة لمواجهة آثار فيروس كورونا الاقتصادية.

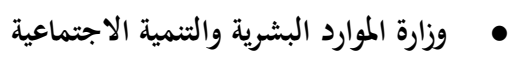
O رفع الإيقاف الخاص بحماية الأجور خلال الفترة الحالية.

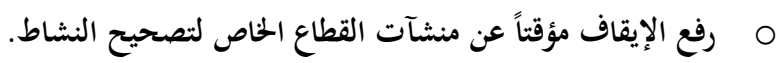
O رفع الإيقاف بسبب عدم دفع الغرامات المتحصلة. O احتساب توظيف السعودي لطاقات بشكل فوري لكل المنشآت O إيقاف الغرامة الخاصة باستقدام العمالة. (أخبار السعودية الإلكترونية) وعن نظام مكافحة الجرائم حددت السلطات السعودية عقوبات التي من شأتها المساس بالنظام العام من خلال : 1. . عقوبة السجن ه سنوات وغرامة ب مليون ريال لمن ينشر فيديوهات مخالفة لأمر منع التجول أو التحريض عليه. 2

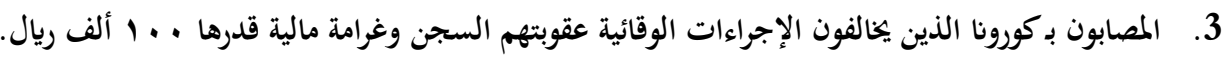

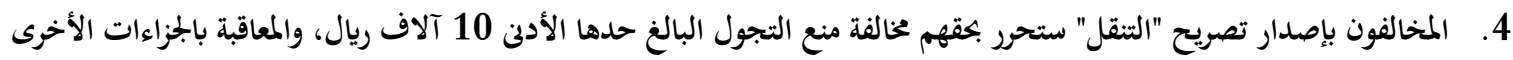
المقررة نظاما (الغرامة المالية، والسجن).

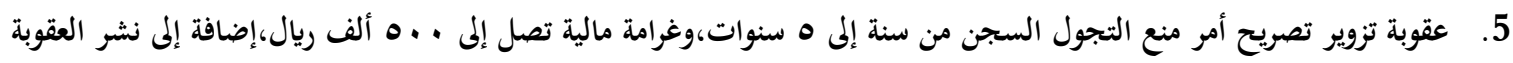

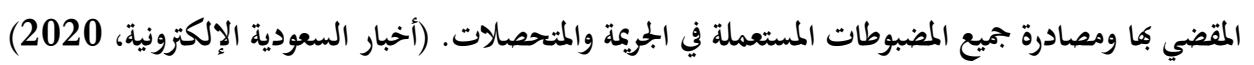




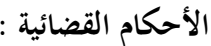

1. تعليق تنفيذ الأحكام القضائية المتصلة بحبس الممدين لقضايا الحق الخاص وتعليق تنفيذ أحكام قضايا الؤية والزيارة الإفراج المؤقت وبشكل فوري عمن حُبس تنفيذاً لتلك الأحكام والأوامر.

2. عليق تنفيذ الأحكام والأوامر القضائية النهائية المتصلة بتمكين الأولاد من زيارة أحد الوالدين المنفصلين. (أخبار السعودية الإلكترونية،

نوع الدراسة:

انطلاقاً من مشكلة الدراسة واتساقاً مع أهدافها تحدد نوع الدراسة في كونها دراسة وصفية للآثار الاجتماعية المترتبة على الإجراءات الاحترازية لإدارة جائحة كورونا في المملكة العربية السعودية.

منهج الدراسة:

اعتمدت الدراسة على منهج المسح الاجتماعي بطريقة العينة العشوائية كونه يتناسب مع أهداف الدراسة وتساؤلائا.

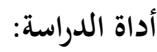

وتتكون استمارة الاستبيان من عدد من المحاور الممستمدة من أهداف وتساؤلات الدراسة، وهي كالثالي:

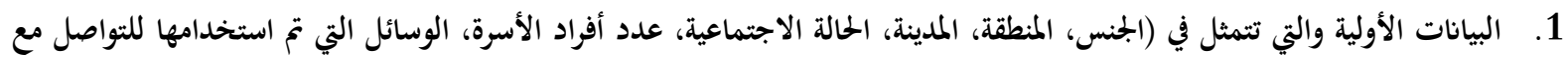

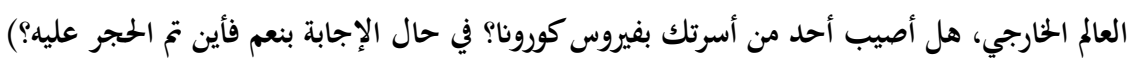

2. محور خاص بالإجابة على تساؤلات الدراسة.

3. خطوات إعداد أداة الدراسة، لإعداد أداة الدراسة (استبيان) تم إتباع الحطوات الدات التالية:

1

2. ت تحديد موضوعات الاستبيان ومحاوره.

3. ت تحديد أوزان فقرات الاستبيان عن طريق الاعتماد على مقياس ليكارت الخماسي الذي يستخدم التدرج التالي: (موافق بشدة-موافق -

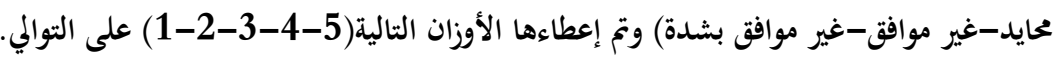

مجتمع الدراسة:

يتكون ججتمع الدراسة من جميع المناطق الإدارية في المملكة العربية السعودية وعددها ثلاثة عشر وهي: الرياض، الدمام، جدة، مكة المكرمة، المدينة

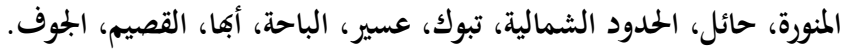

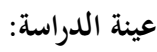

لصعوبة تغطية مجتمع دراسة بهذا الحجم؛ فقد تم سحب عينة ممثلة من جميع المناطق السابقة و عددها 1952.

مجالات الدراسة:

المجال المكاني: عينة من بعض مناطق المملكة العربية السعودية وهم: (الرياض، مكة المكرمة، الملدينة المنورة، القصيم، الشرقية، عسير، تبوك، حائل،

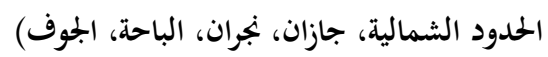


الجمال البشري: عينة من أفراد الجُتمع السعودي ذكورًا وإناثًا الذين تزيد أعمارهم عن 15 سنة. الجحال الزمني: الفترة التي اقتضتها لجمع البيانات من تاريخ 2020/03/30م إلى 2020/04/01م. النتائج العامة المتعلقة بالإجابة على تساؤلات الدراسة الرئيسة والفرعية:

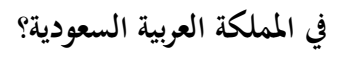
تم القيام بعمليات الإحصاء الوصفي للبيانات التي جمعت من الميدان وكانت النتائج كالتالي:

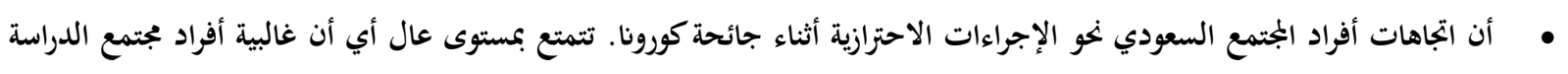
لديهم اتجاهات إيجابية بشكل كبير، نحو هذه الإجراءات الاحترات الإزازية.

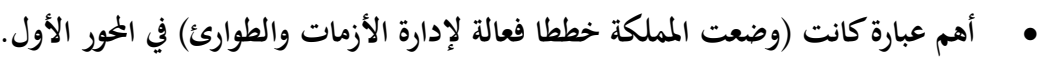

$$
2 \text { 2. لإِجابة على التساؤل الرئيس الثاني: ما هي اتجاهات الجنتمع السعودي نخو الآثار المترتبة للإجراءات الاحترازية في التعامل مع }
$$
جائحة كورونا؟ كان لابد من الإجابة على التساؤلات الفرعية:

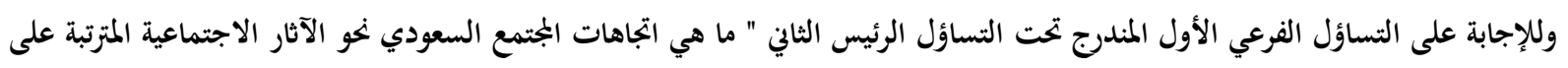

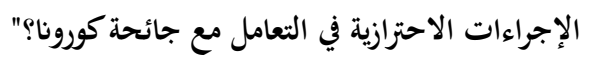

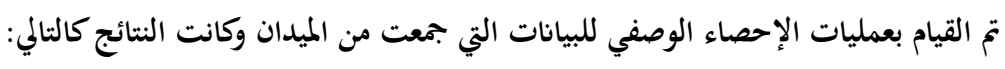

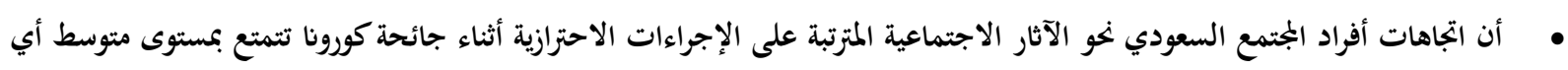

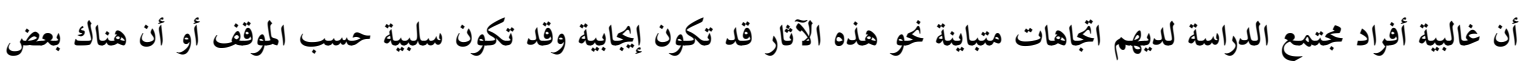

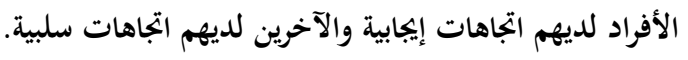
• أهم عبارة كانت " ساهمت وسائل التواصل الاجتماعي في رفع الوعي أثناء جائحة كورونا" في الخور الثاني.

وللإجابة على التساؤل الفرعي الثاني المندرج تحت التساؤل الرئيس الثاني " ما هي اتجاهات البجتمع السعودي نحو الآثار الاقتصادية المترتبة

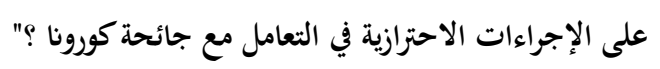

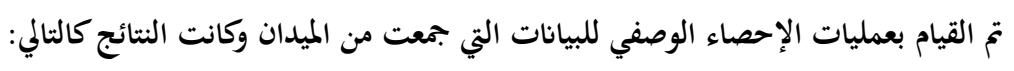

• أن اتجاهات أفراد الجتمع السعودي نخو الآثار الاقتصادية المترتبة على الإجراءات الاحترازية أثناء جائحة كورونا تتمتع بمستوى متوسط أي

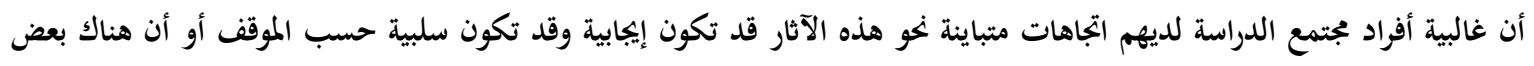

$$
\text { الأفراد لديهم اتجاهات إيجابية والآخرين لديهم اتجاهات سلبية. }
$$

كانت أهم عبارة" أثرت إجراءات حظر التجول والحجر المنزلي على سوق التجارة الالكترونية إيجابيا، في الخور الرابع.

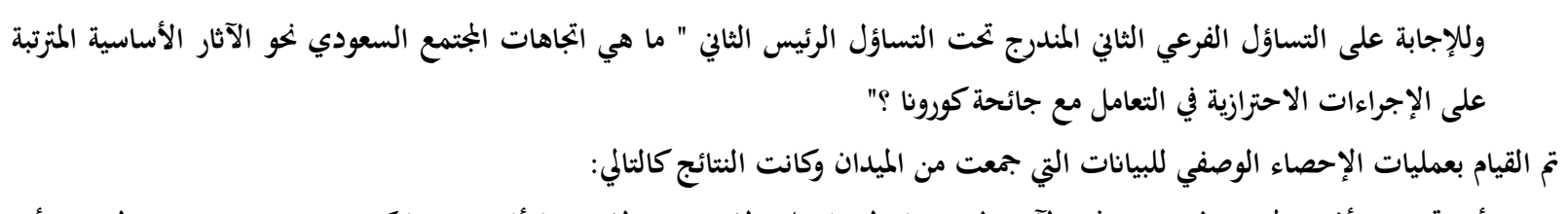

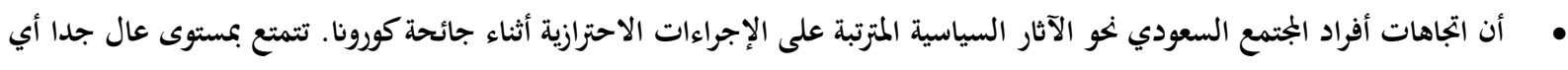

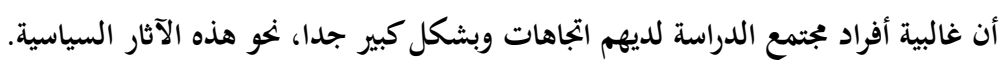

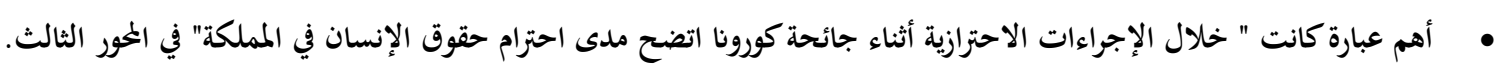

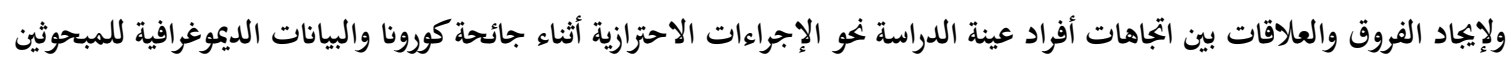


تم القياء بعمليات الإحصاء الاستدلالي فكانت النتائج كالتالي:

عدم وجود فروق ذات دلالة إحصائية بين اتجاهات المبحوثين نخو خدمات الإجراءات الاحترازية أثناء جائحة كورونا تعزى إلى نوع المبحوث.

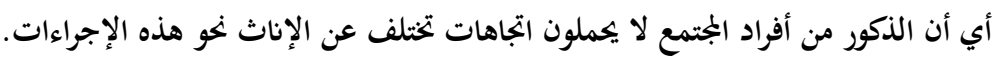

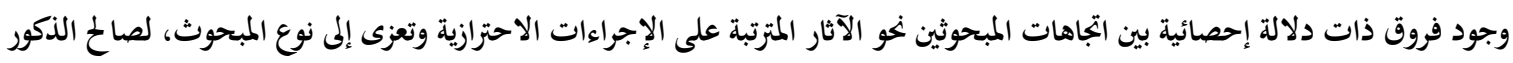
بشكل نسبي. عدم وجود فروق ذات دلالة إحصائية بين المتوسطات الحسابية لمتغير اتجاهات أفراد الجتمع السعودي نحو الإجراءات الاحترازية التي اتخذتها

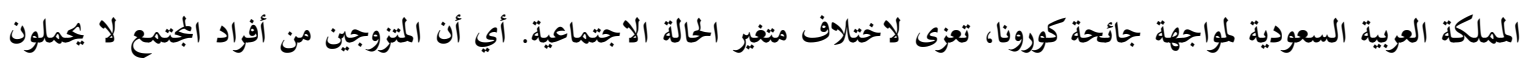
اتجاهات تختلف عن غير المتزوجين نحو هذه الإجراءات.

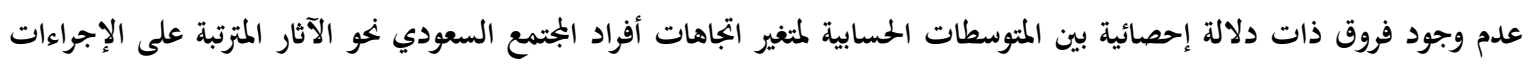

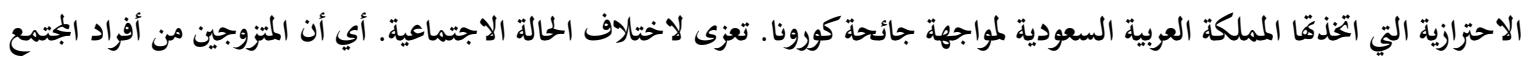
لا يحملون اتجاهات تختلف عن غير المتزوجين نحو هذه الإجراءات.

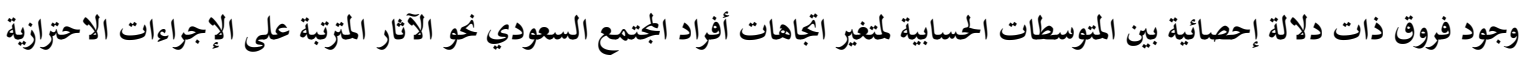

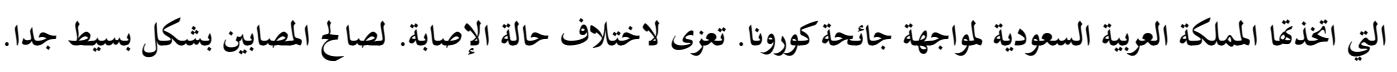

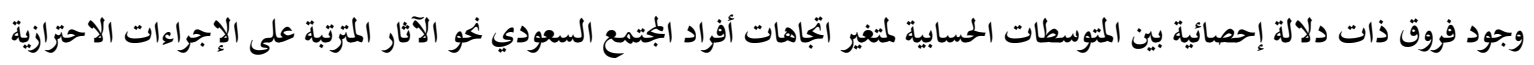

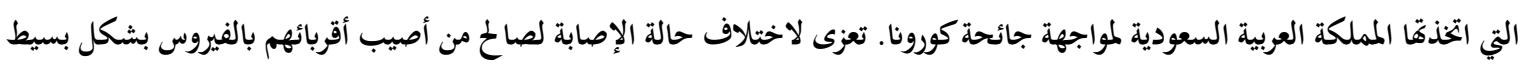

عدم وجود فروق بين متوسطات التجاهات أفراد الجُتمع السعودي نحو الإجراءات الاحترازية والتي تُعزى إلى العمر.

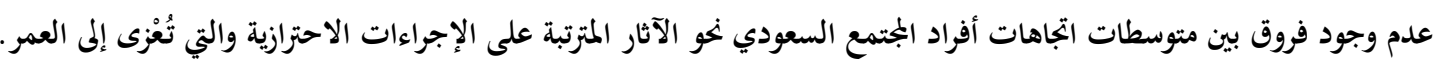

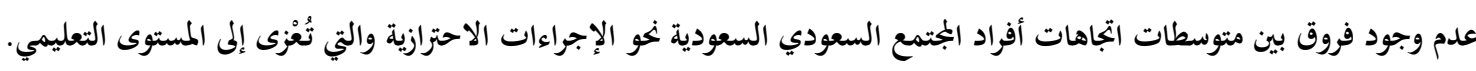

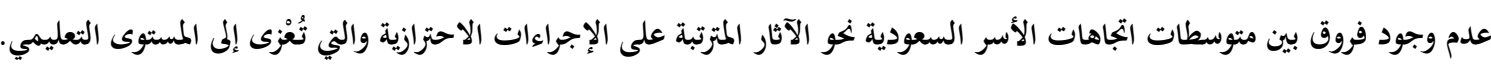

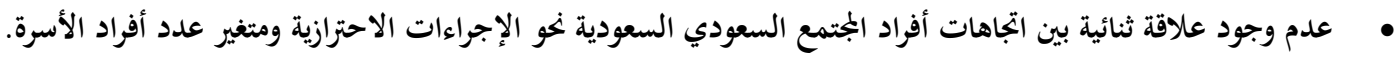

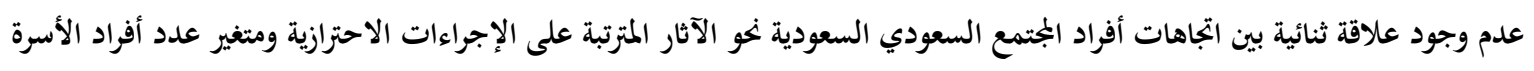

توصيات الدراسة:

تبين من خلال النتائج الدور الكبير والأثر الفعال لوسائل التواصل الاجتماعي في رفع نسبة الوعي بالقضايا الجختمعية، لهذا توصي الدراسة باستغلال هذه النتيجة لإعادة تشكيل الصورة الذهنية للقدوات على التئ مستوى الجنتمع.

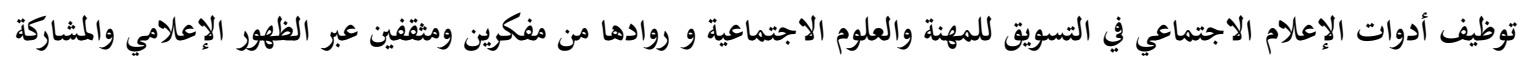

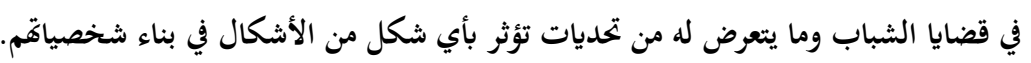

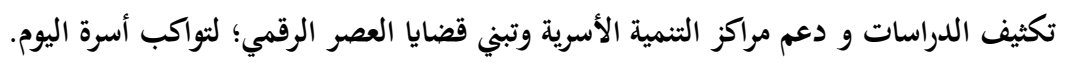

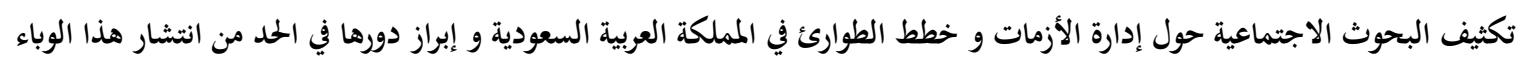
على مستوى المملكة و المستوى العالمي.

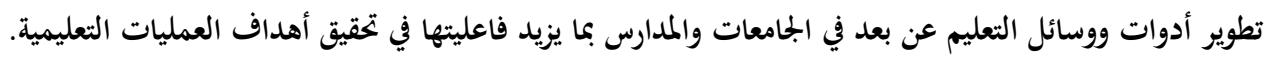

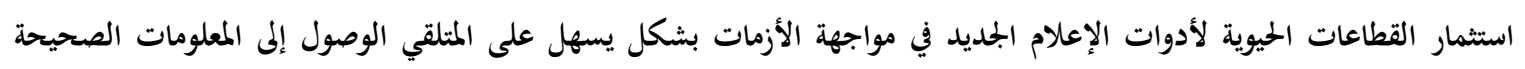
والموثوقة. زيادة التوجه نحو التحول الرقمي في مختلف القطاعات الحيوية لدى الدولة بعد انتهاء الأزمة بما يكفل وصول الخدمات لمستحقيها بسرعة 
• سن القوانين والتشريعات المنظمة لسوق التجارة الإلكترونية وعمليات البيع والشراء من خلالها.

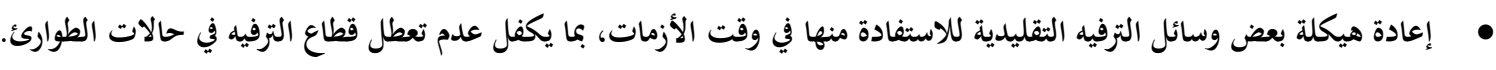

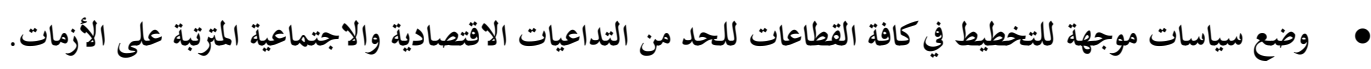

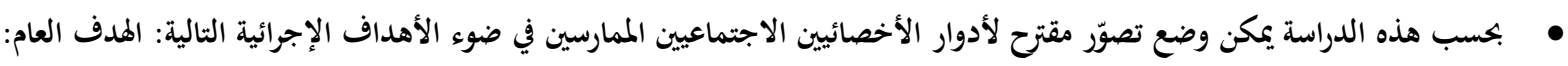
إدارة مخاوف الأنساق الصغرى في الجمتمع، وتحسين الممارسة المهنية:

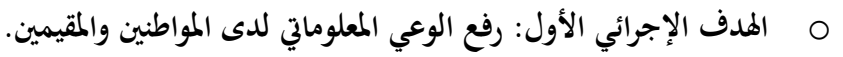

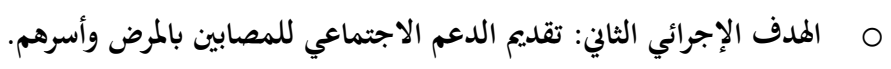

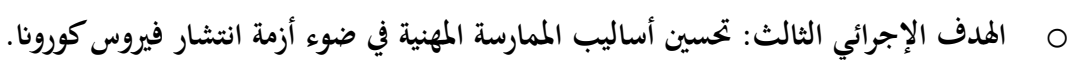

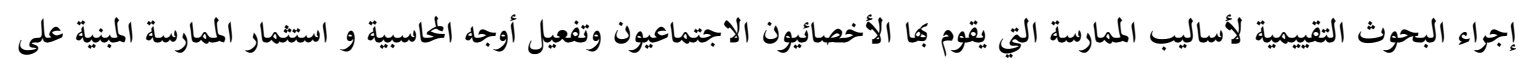
البراهين. 
المراجع

- الدسوقي، سميرة إبراهيم. (3، 2013). التخطيط الاستراتيجي وإدارة الأزمات المجتمعية. المؤتمر العلمي الدولي السادس والعشرون للخدمة الاجتماعية (الصفحات 4308-4219). حلوان: جامعة حلوان-كلية الحذدمة الاجتماعية. - الديب، محمد نجيب. (1997). الحدمة الإجتماعية المدرسية. مصر : مكتبة الأنجلو. - الزامل، الجوهرة عبد العزيز (2016). التخطيط لمواجهة الأزمات والكوارث في المملكة العربية السعودية: دراسة مطبقة على المسئولين والخبراء في

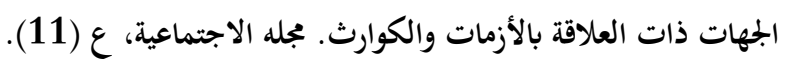
- السروجي، طلعت مصطفى. (2013). إدارة المؤسسات الاجتماعية. عمّان: دار الفكر ناشرون وموزعون. - السكارنه، بلال خلف (2017). خطط الطوارئ ودورها في مواجهة الأزمات، الأردن.مركز البحث وتطوير الموارد البشرية. مجلة رماح للبحوث والدراسات. ع ع24

- الفكي، عبد الناصر علي (2016). الثقافة الجتمعية ومعدلات الإصابة بالأمراض في أفيقيا (الإيبولا: ليبيريا- الإيدز: إثيوبيا- السحائي:

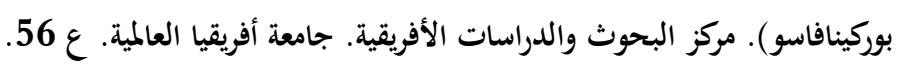
- المهالا، محمد بن عبد العزيز.(2016). التدابير الاحترازية: دراسة مقارنة. جامعة الإمام محمد بن سعود الإسلامية. - الهاشيم، مصعب حبيب (2017). دور القوانين والتشريعات الدولية والحلية في مواجهة أزمات الكوارث. مجلة العلوم الإنسانية. مج 18، ع (1). - بافيل، عبد الله بن عمر (2013) تجربة جامعة الملك عبد العزيز في مجلات الطوارئ و الكوارث. دراسة منشورة، جامعة الإمام محمد بن سعود الإسلامية، المؤتمر السعودي الدولي الأول لإدارة الأزمات والكوارث. - باين، مالكوم وآخرون. (1998). نظرية الحدمة الإجتماعية المعاصرة. مصر : المكتب العلمي للكمبيوتر والنشر والثوزيع. - برنت، د.ف.م. (2019) رحلة الإنسان مع الفيروس. القاهرة: وكالة الصحافة العببة. - جبر، احمد عبد الرازق (2009) الطاعون الحطر القادم. بحث منشور، جامعة المنصورة، كلية الزراعة، قسم إنتاج الحيوان. - جمجوم، غازي عبداللطيف (2014) كورونا ميرس والاستفادة من دروس كورونا سارس. الإعجاز العلمي، ع47. - خلف الله، شعبان (2014) الأمراض السارية التي تنتقل إلى الإنسان من الحيوانات ومنتجاتًا. القاهرة: دار الكتب العلمية. - خليل، أمال حلمي سليمان (2013) فيروس كورونا الجديد " متلازمة الشرق الأوسط التنفسية "، دراسة في الجغرافية الطبية، رسائل جغرافية، الرسالة 398.

- رشوان، عبدالمنصف حسن و القرين، محمد مسفر. (2013). المداخل العلاجية المعاصرة مع الأفراد والأسر. الرياض: مكتبة الرشد. - رشيد، إيناس. (• • (ץ). فيروس كورونا، جامعة تكريت. - عبدالعزيز، ليلى السيد (2018) الأمراض والأوبئة وآثارها على الجنتمع المصري (1798 - 1813م). دورية كان التاريخية،ع 39. 
- عزام، شعبان عبد الصادق عوض. (2015). تصور لمؤشرات دور مقترح من منظور نموذج التدخل في الأزمات لإدارة الغضب لدى الزوج في فترة التقاضي للخلع. مصر: الجمعية المصرية للأخصائيين الاجتماعيين. - فيلبي، هاري سانت جون (2002) قلب الجزيرة العربية. الجزء الأول، الرياض، العبيكان للنشر. - قاسمي، لبنى و سلطاني، كاميليا (2015). دور شبكات التواصل الاجتماعي في التوعية الصحية حول مرض الإيبولا: الصفحات الفيسبوكية نموذجا، رسالة ماجستير في علوم الاتصال، جامعة العربي بن مهيدي أم البواقي, الجزائر. - لطف الله، نادية سمعان (2010) فاعلية وحدة عن الأمراض الوبائية في ضوء المعايير القومية في تنمية المعارف ومهارات إدارة الأزمات الصحية لدى الطالب المعلم. دراسة منشورة، جامعة عين شنمس، كلية التربية، الجمعية المصرية للمناهج وطرق التدريس. - متولي، ماجدة وآخرون (2009) ممارسة الحخدمة الاجتماعية مع الأفراد والعائلات. القاهرة، الشركة العربية المثحدة للتسويق والتوريد. - محمد، محمد عبدالفتاح. (2012). إدارة الجودة الشاملة وبناء قدرات المنظمات الاجتماعية . الإسكندرية : المكتب الجامعي الحديث. - منظمة الأغذية والزراعة للأمم المتحدة (9 ( ب) تبني فج متعدد القطاعات "لتوحيد الأداء في مجال الصحة: دليل ثلاثي لمواجهة الأمراض حيوانية في البلدان. روما: قسم الطباعة والنشر. - الجريوي، خالد (2011). إدارة الأزمات والكوارث البيئية: دراسة تطبيقية في المملكة العربية السعودية، رسالة دكتوراه غير منشورة، السودان، جامعة ام درمان ام درمان الإسلامية .

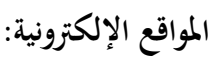

https://ara.tv/ysng2 العربية ( السعودية .. أول إصابة بكورونا لمواطن قادم من إيران) استرجعت بتاريخ (2020/4/10) https://ara.tv/2cxmt العربية (الملك سلمان: نمر بمرحلة صعبة من تاريخ العالم لكنها ستمضي) تم الاسترجاع (2020/3/19 Www.hespress.com النشرة البريدية لجريده هسبريس -

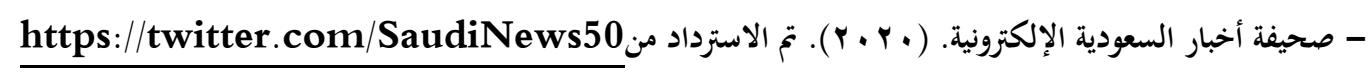
https://twitter.com/spagov صفحة وكالة الأنباء السعودية واس على التويتر - مركز الدراسات الاستراتيجية. (2020). نظرة الأردنيين وتعاملهم مع فيروس كورونا. دائرة استطلاعات الرأي العام والمسوح الميدانية في مركز

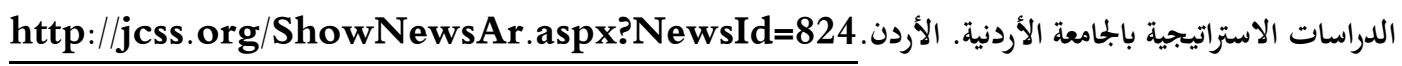
https://cutt.us/nmEAT منظمة الصحة العالمية (2020) مرض فيروس كورونا (كوفيد-19)، استرجعت بتاريخ (2020/4/4) https://www.almaany.com/ar/dict/ar-ar/ موقع المعاني .تم الاسترداد من - موقع هيئة الصحة بدبي. (• • • (Y). تم الاسترداد من - 
https://www.dha.gov.ae/Covid19/Pages/arcorona.aspx موقع هيئة الصحة بدبي. (•r • r). تم الإسترداد من - موقع وزارة الصحة (2020) التحديث اليومي للحالات استرجعت بتاريخ (2020/4/15) https://covid19.cdc.gov.sa/ar/daily-updates-ar/.

Www.moh.gov.sa موقع وزاره الصحة السعودية - وكالة الأنباء السعودية واس (اقتصادي / المملكة العبية السعودية تدعو لعقد قمة استثنائية لقادة مجموعة العشرين حول فيروس كورونا) تم https://www.spa.gov.sa/2048787 (2020/3/18) الاسترجاع - وكالة الأنباء السعودية واس (عام / إطلاق منصة وطنية لتمكين الراغبين في التطوع الصحي) تم الاسترجاع (2020/4/9) https://www.spa.gov.sa/2071979

- وكالة الأنباء السعودية واس (عام / الصحف السعودية / إضافة أولى) تم الاسترجاع (2020/4/9) https://www.spa.gov.sa/2071839 - وكالة الأنباء السعودية واس (عام / تعليق الدراسة في جميع مدارس ومؤسسات التعليم العام والأهلي والجامعي والفني في المملكة اعتباراً من يوم غدٍ https://www.spa.gov.sa/2044433 الاثنين وحتى إشعار آخر) تم الاسترجاع (2020/3/8

- وكالة الأنباء السعودية واس (عام / حكومة المملكة تقرر تعليق الحضور لمقرات العمل في كافة الجهات الحكومية لمدة (16) يومًا عدا القطاعات https://www.spa.gov.sa/2047983 الصحية والأمنية والعسكرية ومركز الأمن الإلكتروني) تم الاسترجاع (2020/3/16) - وكالة الأنباء السعودية واس (عام / مصدر مسئول بوزارة الداخلية: تعليق العمرة مؤقتًا للمواطنين والمقيمين في المملكة) تم الاسترجاع بتاريخ https://www.spa.gov.sa/2042784 $(2020 / 3 / 4)$ 